\title{
Linking Molecular Behavior to Macroscopic Properties in Ideal Dynamic Covalent Networks
}

\author{
Bruno Marco-Dufort, Ramon Iten, Mark W. Tibbitt* \\ Macromolecular Engineering Laboratory, Department of Mechanical and Process Engineering, ETH Zurich, \\ Zurich 8092, Switzerland.
}

\section{Experimental and Supporting Information}




\section{Contents}

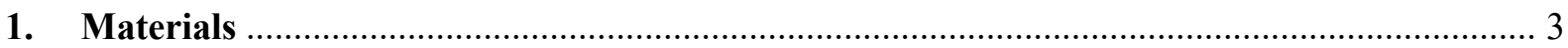

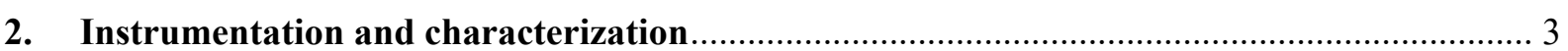

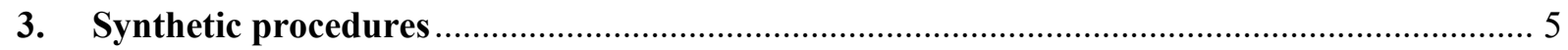

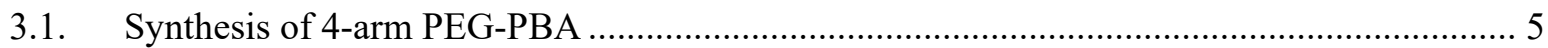

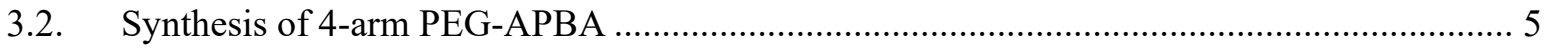

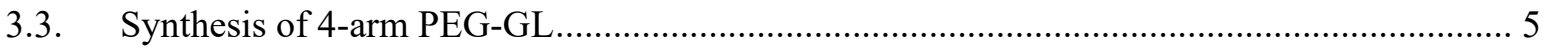

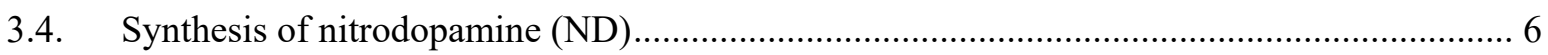

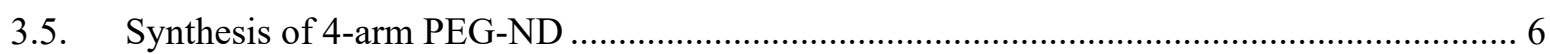

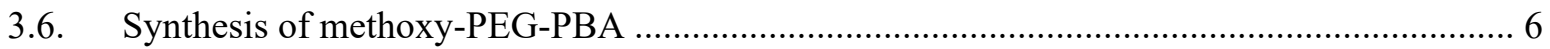

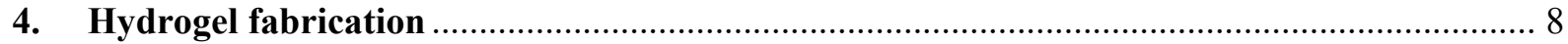

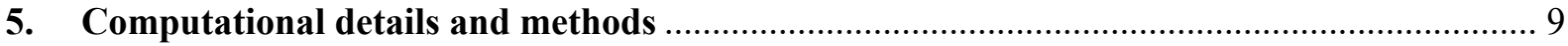

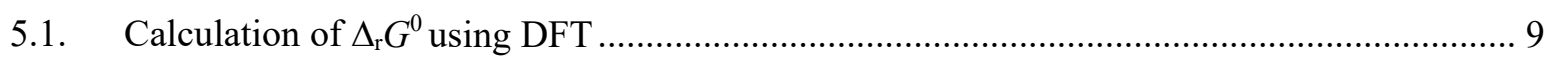

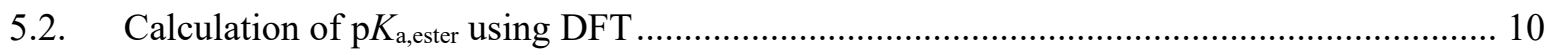

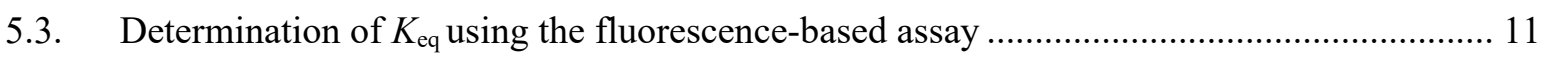

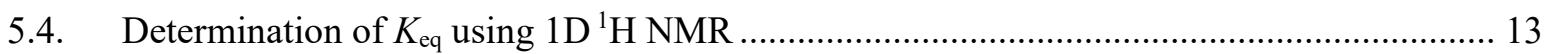

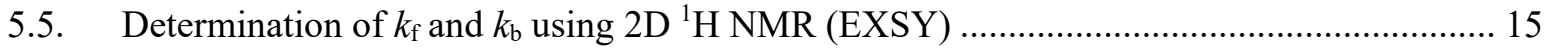

5.6. Determination of $\Delta G_{\mathrm{b}}{ }^{\ddagger}, \Delta H_{\mathrm{b}}{ }^{\ddagger}$, and $\Delta S_{\mathrm{b}}^{\ddagger}$ from shear rheometry .......................................... 16

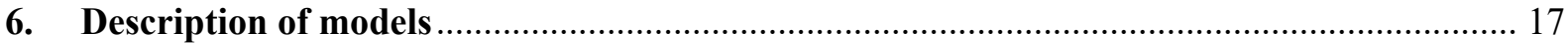

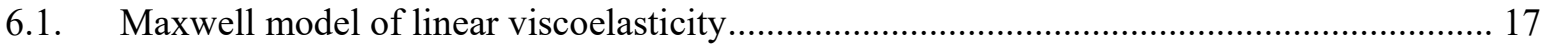

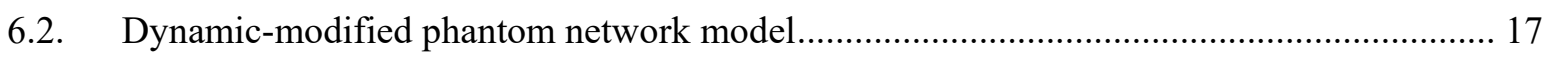

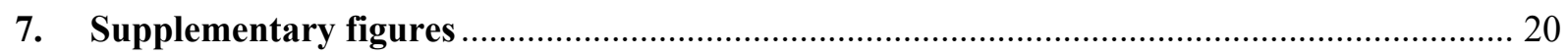

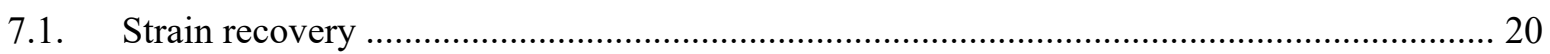

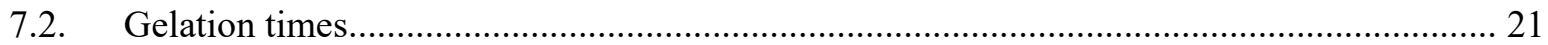

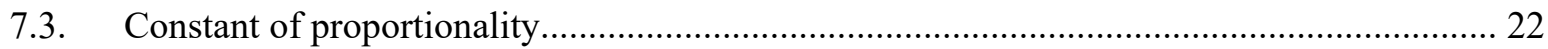

7.4. Activation energies of PEG-PBA/ND and PEG-APBA/ND ............................................ 23

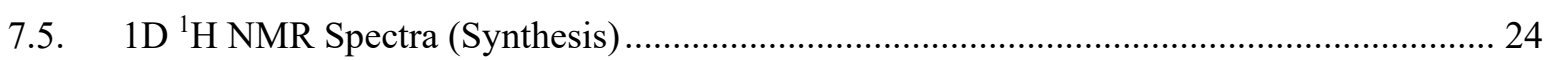

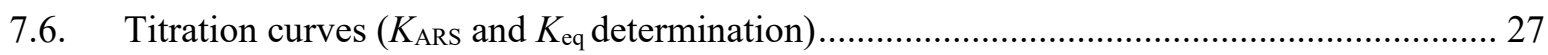

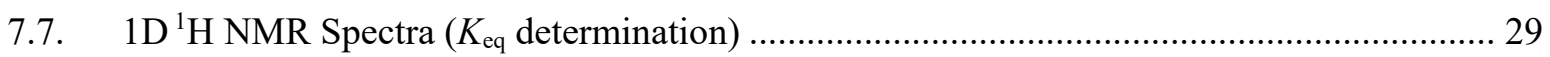

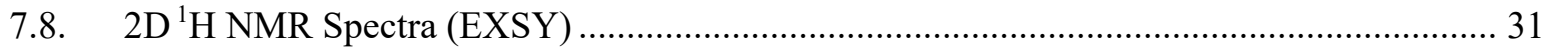

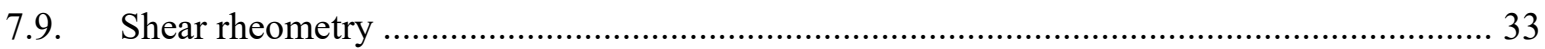

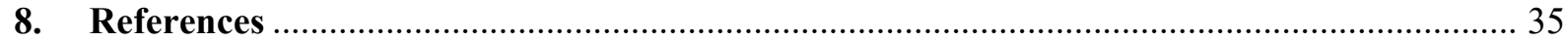




\section{Materials}

Synthetic procedures: 4-Arm PEG-NH${ }_{2} \mathrm{HCl}\left(M_{\mathrm{n}}=10000 \mathrm{~g} \mathrm{~mol}^{-1}\right)$, 4-arm PEG-p-nitrophenylcarbonate (PEG-NPC; $M_{\mathrm{n}}$ $\left.=10000 \mathrm{~g} \mathrm{~mol}^{-1}\right)$, and methoxy-PEG-NH $2 \mathrm{HCl}\left(M_{\mathrm{n}}=10000 \mathrm{~g} \mathrm{~mol}^{-1}\right)$ were purchased from JenKem Technology USA. 4Carboxyphenylboronic acid, 1-hydroxybenzotriazole hydrate (HOBt), O-(benzotriazol-1-yl)-N,N,N',N'tetramethyluronium hexafluorophosphate (HBTU), triethylamine, 2-formylphenylboronic acid, sodium borohydride $\left(\mathrm{NaBH}_{4}\right), \mathrm{D}-(+)$-gluconic acid $\delta$-lactone (gluconolactone; GL), 2,2-dihydroxyindane-1,3-dione (ninhydrin), dopamine hydrochloride, sodium nitrite $\left(\mathrm{NaNO}_{2}\right)$, sulfuric acid, hydrochloric acid $(\mathrm{HCl})$, sodium hydroxide $(\mathrm{NaOH})$, dichloromethane (DCM), dimethylformamide (DMF), methanol $(\mathrm{MeOH})$, and deuterated water $\left(\mathrm{D}_{2} \mathrm{O}\right)$ were purchased from Sigma-Aldrich. Regenerated cellulose dialysis tubing (MWCO $1 \mathrm{kDa}$ ) was purchased from Spectrum Labs.

Buffer components: Acetic acid (glacial), sodium acetate, 2-(N-morpholino)ethanesulfonic acid (MES) sodium salt, 4(2-hydroxyethyl)piperazine-1-ethanesulfonic acid (HEPES), sodium carbonate, sodium hydrogen carbonate (bicarbonate), sodium phosphate, and potassium chloride $(\mathrm{KCl})$ were purchased from Sigma-Aldrich.

Fluorescence and NMR measurements: Alizarin Red S (ARS), D-(-)-fructose (fructose), phenylboronic acid (PBA), and deuterated dimethyl sulfoxide $\left(\left(\mathrm{CD}_{3}\right)_{2} \mathrm{SO}\right)$ were purchased from Sigma-Aldrich.

\section{Instrumentation and characterization}

NMR: ${ }^{1} \mathrm{H}$ 1D and 2D NMR spectra were acquired on a Bruker Avance III 400 (Bruker BioSpin GmbH). The residual undeuterated solvent peaks were used for references (4.7 ppm for $\mathrm{D}_{2} \mathrm{O}$ and $2.5 \mathrm{ppm}$ for $\left.\left(\mathrm{CD}_{3}\right)_{2} \mathrm{SO}\right)$. The following abbreviations were used to denote multiplicities: $\mathrm{s}=$ singlet, $\mathrm{d}=$ doublet, $\mathrm{t}=$ triplet, $\mathrm{m}=$ multiplet and $\mathrm{br}=$ broad. Relative integration is reported in number of protons $(\mathrm{H})$.

DFT calculations: All DFT calculations were performed using the Gaussian 09 software package. ${ }^{1}$ The structures of the boronic acids, diols, and boronic esters (both in their neutral and anionic forms) were optimized using the PBE0 functional. ${ }^{2}$ All atoms were represented by the Def2TZVP basis set. ${ }^{3}$ The effects of solvent were treated implicitly by using the PCM model (water). ${ }^{4}$ Free energies, $G$, were calculated at a temperature of $298.15 \mathrm{~K}$ and a pressure of 1 atmosphere.

pH meter: pH was determined using a calibrated pH 1100L precision pH meter (VWR International GmbH; Dietikon, Switzerland). 
Plate reader: Fluorescence measurements were acquired with a Hidex Sense Microplate Reader (Hidex; Turku, Finland) using 96-well plates (Microfluor ${ }^{\circledR} 1$ black plates; flat bottom), with the samples being excited at $460 \mathrm{~nm}$ and emission being measured at $575 \mathrm{~nm}$.

Rheometer: Rheometric characterization was performed using a strain-controlled shear rheometer (MCR 502; AntonPaar; Zofingen, Switzerland) equipped with a Peltier stage to control the temperature $\left(T=5-50{ }^{\circ} \mathrm{C}\right)$. All experiments were performed at $25{ }^{\circ} \mathrm{C}$ unless stated otherwise. Silicone oil was applied during the experiment to prevent drying of samples. All measurements were performed using a $25 \mathrm{~mm}$ parallel plate geometry with a gap of $0.5 \mathrm{~mm}$. Motor adjustments were performed prior to each experiment. The samples were prepared at least $1 \mathrm{~h}$ before each experiment to allow for complete gelation. The samples were loaded by placing them directly on the plate and lowering the geometry to the desired gap. Once loaded, the samples were equilibrated to the set temperature for at least $15 \min (\gamma=0.1 \% ; \omega=$ $1 \mathrm{rad} \mathrm{s}^{-1}$ ). Strain sweep experiments (SS) were performed at $\omega=10 \mathrm{rad} \mathrm{sec}^{-1}$ for $\gamma=0.001-1000 \%$. Frequency sweep experiments (FS) were performed at $\gamma=1 \%$ (within the linear viscoelastic region, as determined from the SS experiments) for $\omega=100-0.01 \mathrm{rad} \mathrm{s}^{-1}$. Strain recovery experiments (SR) were performed at $\omega=10 \mathrm{rad} \mathrm{s}^{-1}$ by alternating periods of high strain $(\gamma=100 \%)$ and low strain $(\gamma=1 \%)$ for 10 cycles. Stress relaxation experiments (RX) were performed by applying $\gamma=10 \%$ on the sample and holding it at that strain. The decay of the stress $(\sigma)$ over time was monitored by measuring the relaxation modulus $G(t)$ every $0.25 \mathrm{~s}$ for a total duration of $1 \mathrm{~h}$. To characterize the gelation time, time sweep experiments (TS) were performed. Liquid formulations of the two gel precursors (boronic acid and diol; $\mathrm{pH}$ adjusted) were pipetted on the plate. After lowering the geometry to the desired gap and applying silicone oil, the samples were monitored every $1 \mathrm{~s}$ for $4 \mathrm{~h}\left(\gamma=1 \% ; \omega=10 \mathrm{rad} \mathrm{s}^{-1}\right)$. 


\section{Synthetic procedures}

1D ${ }^{1} \mathrm{H}$ NMR spectra for all the synthesized compounds are found in SI Section 7.5.

\subsection{Synthesis of 4-arm PEG-PBA}

The synthesis of 4-arm PEG-PBA was performed according to a published procedure with some modifications. ${ }^{5}$ 4-Arm PEG-NH $2 \mathrm{HCl}\left(2.0 \mathrm{~g}, 0.2 \mathrm{mmol} ; M_{\mathrm{n}}=10000 \mathrm{~g} \mathrm{~mol}^{-1}\right)$ was dissolved in DCM $(10 \mathrm{~mL})$ in a round-bottom flask equipped with a stir bar. 4-Carboxyphenylboronic acid (199 mg, $1.2 \mathrm{mmol}), \mathrm{HOBt}$ (162 mg, $1.2 \mathrm{mmol})$, HBTU (455 $\mathrm{mg}, 1.2 \mathrm{mmol})$ and triethylamine $(0.6 \mathrm{~mL}, 4.3 \mathrm{mmol})$ were added sequentially to the PEG solution, followed by the addition of DMF $(10 \mathrm{~mL})$ to solubilize the HBTU and the phenylboronic acid. The reaction was carried out at room temperature for $12 \mathrm{~h}$. After evaporation of the DCM, the remaining product was dissolved in deionized (DI) water; the pH was balanced to 7 (using $1 \mathrm{~m} \mathrm{NaOH})$; dialyzed against DI water for $72 \mathrm{~h}$ (1 kDa MWCO); filtered $(0.2 \mu \mathrm{m})$; and then lyophilized to yield a white powder. ${ }^{1} \mathrm{H}$ NMR $\left(400 \mathrm{MHz}, \mathrm{D}_{2} \mathrm{O}\right): \delta$ 7.8-7.7 (m, $\left.16 \mathrm{H}\right), 3.6(\mathrm{~m}, 900 \mathrm{H}), 2.9(\mathrm{~s}, 8 \mathrm{H})$. The degree of functionalization determined from ${ }^{1} \mathrm{H}$ NMR was $\approx 80 \%$ (theoretical $\left.M_{\mathrm{n}}=10,592 \mathrm{~g} \mathrm{~mol}^{-1}\right)$.

\subsection{Synthesis of 4-arm PEG-APBA}

The synthesis of 4-arm PEG-APBA was performed according to a published procedure with some modifications. ${ }^{5}$ 4-Arm PEG- $\mathrm{NH}_{2} \mathrm{HCl}\left(2.0 \mathrm{~g}, 0.2 \mathrm{mmol} ; M_{\mathrm{n}}=10000 \mathrm{~g} \mathrm{~mol}^{-1}\right)$ was dissolved in $\mathrm{MeOH}(10 \mathrm{~mL})$ in a roundbottom flask equipped with a stir bar, followed by the addition of 2-formylphenylboronic acid (180 mg, $1.2 \mathrm{mmol})$ and triethylamine $(0.5 \mathrm{~mL}, 3.6 \mathrm{mmol})$. The reaction was left to proceed for $72 \mathrm{~h}$ at room temperature under argon gas. Afterwards, the reaction was cooled on ice to $4{ }^{\circ} \mathrm{C}$, and $\mathrm{NaBH}_{4}(90 \mathrm{mg}, 2.4 \mathrm{mmol})$ was added portion wise. After removing the ice bath, the reaction was left to proceed for $12 \mathrm{~h}$ at room temperature. After evaporation of the $\mathrm{MeOH}$, the remaining product was dissolved in DI water; the $\mathrm{pH}$ was balanced to 7 (using $1 \mathrm{~m} \mathrm{HCl}$ ); dialyzed against DI water for $72 \mathrm{~h}(1 \mathrm{kDa} \mathrm{MWCO})$; filtered $(0.2 \mu \mathrm{m})$; and then lyophilized to yield a white powder. ${ }^{1} \mathrm{H}\left(400 \mathrm{MHz}, \mathrm{D}_{2} \mathrm{O}\right): \delta 7.4-$ $7.1(\mathrm{~m}, 16 \mathrm{H}), 4.0(\mathrm{~s}, 8 \mathrm{H}), 3.6(\mathrm{~m}, 892 \mathrm{H}), 3.0(\mathrm{t}, 8 \mathrm{H})$. The degree of functionalization determined from ${ }^{1} \mathrm{H}$ NMR was $\approx 85 \%$ (theoretical $\left.M_{\mathrm{n}}=10,480 \mathrm{~g} \mathrm{~mol}^{-1}\right)$.

\subsection{Synthesis of 4-arm PEG-GL}

The synthesis of 4-arm PEG-GL was performed according to a published procedure with some modifications. ${ }^{5}$ 4-Arm PEG-NH $2 \mathrm{HCl}\left(2.0 \mathrm{~g}, 0.2 \mathrm{mmol} ; M_{\mathrm{n}}=10000 \mathrm{~g} \mathrm{~mol}^{-1}\right)$ was dissolved in $\mathrm{MeOH}(50 \mathrm{~mL})$ in a round-bottom flask equipped with a stir bar, followed by the addition of D-(+)-gluconic acid $\delta$-lactone (285 mg, $1.6 \mathrm{mmol})$ and triethylamine $(1.0 \mathrm{~mL}, 7.2 \mathrm{mmol})$. The reaction was allowed to proceed for $72 \mathrm{~h}$ at room temperature. Afterwards, the extent of the reaction was monitored by performing a ninhydrin test, to detect the presence of free amines. If free amines persisted 
(blue $=$ unreacted amines still present; yellow/colorless = amines successfully coupled), additional D-(+)-gluconic acid $\delta$-lactone $(285 \mathrm{mg}, 1.6 \mathrm{mmol})$ and triethylamine $(1.0 \mathrm{~mL}, 7.2 \mathrm{mmol})$ were added, and the reaction was left to proceed for another 24-72 $\mathrm{h}$ at room temperature. After evaporation of the $\mathrm{MeOH}$, the remaining product was dissolved in DI water; the $\mathrm{pH}$ was balanced to 7 (using $1 \mathrm{~m} \mathrm{NaOH})$; dialyzed against DI water for $72 \mathrm{~h}(1 \mathrm{kDa} \mathrm{MWCO})$; filtered $(0.2$ $\mu \mathrm{m})$; and then lyophilized to yield a white powder. ${ }^{1} \mathrm{H}\left(400 \mathrm{MHz}, \mathrm{D}_{2} \mathrm{O}\right): \delta 4.3(\mathrm{~d}, 4 \mathrm{H}), 4.0(\mathrm{t}, 4 \mathrm{H}), 3.6(\mathrm{~m}, 924 \mathrm{H})$. The degree of functionalization determined from ${ }^{1} \mathrm{H}$ NMR was $\approx 85 \%$ (theoretical $\left.M_{\mathrm{n}}=10,713 \mathrm{~g} \mathrm{~mol}^{-1}\right)$.

\subsection{Synthesis of nitrodopamine (ND)}

The synthesis of nitrodopamine (ND) was performed according to a published procedure with some modifications. ${ }^{6}$ Dopamine hydrochloride $(500 \mathrm{mg}, 2.6 \mathrm{mmol})$ and $\mathrm{NaNO}_{2}(630 \mathrm{mg}, 9.1 \mathrm{mmol})$ were dissolved in DI water $(15 \mathrm{~mL})$ in a round-bottom flask equipped with a stir bar and cooled on ice to $4{ }^{\circ} \mathrm{C}$. Then, $20 \%(\mathrm{v} / \mathrm{v})$ sulfuric acid $(2.5 \mathrm{~mL})$ was carefully added under vigorous stirring. After 15 min on ice at $4{ }^{\circ} \mathrm{C}$, precipitates were collected by vacuum filtration and washed with cold water three times and then with cold $\mathrm{MeOH}$ three times to yield an orange solid $(\approx 45 \%$ yield; $\left.198.06 \mathrm{~g} \mathrm{~mol}^{-1}\right) .{ }^{1} \mathrm{H}\left(400 \mathrm{MHz},\left(\mathrm{CD}_{3}\right)_{2} \mathrm{SO}\right): \delta 7.4(\mathrm{~s}, 1 \mathrm{H}), 6.5(\mathrm{~s}, 1 \mathrm{H}), 3.0(\mathrm{~m}, 4 \mathrm{H})$.

\subsection{Synthesis of 4-arm PEG-ND}

The synthesis of 4-arm PEG-ND was performed according to a published procedure with some modifications. ${ }^{6}$ 4-Arm PEG-NPC (250 mg, $\left.0.025 \mathrm{mmol} ; M_{\mathrm{n}}=10000 \mathrm{~g} \mathrm{~mol}^{-1}\right)$ was dissolved in DMF $(2 \mathrm{~mL})$ in a round-bottom flask equipped with a stir bar, followed by the addition of nitrodopamine $(60 \mathrm{mg}, 0.3 \mathrm{mmol})$ and triethylamine $(85 \mu \mathrm{L}, 0.6$ mmol). The reaction was allowed to proceed for $48 \mathrm{~h}$ at room temperature under argon gas. The remaining product was dissolved in DI water; dialyzed against DI water for $72 \mathrm{~h}(1 \mathrm{kDa} \mathrm{MWCO})$; filtered $(0.2 \mu \mathrm{m})$; and then lyophilized to yield a dark yellow powder. ${ }^{1} \mathrm{H}\left(400 \mathrm{MHz}, \mathrm{D}_{2} \mathrm{O}\right): \delta 7.6(\mathrm{~s}, 4 \mathrm{H}), 6.7(\mathrm{~s}, 4 \mathrm{H}), 4.0(\mathrm{br} \mathrm{s}, 8 \mathrm{H}), 3.8-3.4(\mathrm{~m}, 900 \mathrm{H}), 3.3(\mathrm{t}$, $8 \mathrm{H}), 3.0(\mathrm{t}, 8 \mathrm{H})$. The degree of functionalization determined from ${ }^{1} \mathrm{H}$ NMR was $\approx 70-75 \%$ (theoretical $M_{\mathrm{n}}=10,901 \mathrm{~g}$ $\left.\mathrm{mol}^{-1}\right)$.

\subsection{Synthesis of methoxy-PEG-PBA}

The synthesis of methoxy-PEG-PBA was performed according to a published procedure with some modification. ${ }^{5}$ Methoxy-PEG-NH${ }_{2} \mathrm{HCl}\left(0.5 \mathrm{~g}, 0.05 \mathrm{mmol} ; M_{\mathrm{n}}=10000 \mathrm{~g} \mathrm{~mol}^{-1}\right)$ was dissolved in $\mathrm{DCM}(5 \mathrm{~mL})$ in a roundbottom flask equipped with a stir bar. 4-Carboxyphenylboronic acid (12.4 mg, $0.075 \mathrm{mmol}), \mathrm{HOBt}(10.1 \mathrm{mg}, 0.075$ mmol), HBTU (28.4 mg, $0.075 \mathrm{mmol})$ and triethylamine $(50 \mu \mathrm{L}, 0.36 \mathrm{mmol})$ were added sequentially to the PEG solution, followed by the addition of DMF $(10 \mathrm{~mL})$ to solubilize the HBTU and the phenylboronic acid. The reaction was carried out at room temperature for $12 \mathrm{~h}$. After evaporation of the DCM, the remaining product was dissolved in DI

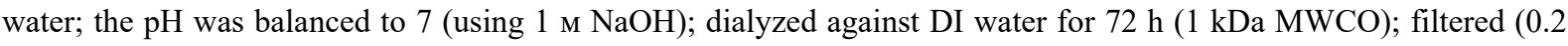


$\mu \mathrm{m})$; and then lyophilized to yield a white powder. ${ }^{~} \mathrm{H}$ NMR (400 MHz, $\left.\mathrm{D}_{2} \mathrm{O}\right): \delta 7.8-7.7(\mathrm{~m}, 4 \mathrm{H}), 3.6(\mathrm{~m}, 909 \mathrm{H}), 3.3$ (s, $3 \mathrm{H}$ ). The degree of functionalization determined from ${ }^{1} \mathrm{H}$ NMR was $\approx 80 \%\left(\right.$ theoretical $\left.M_{\mathrm{n}}=10,179 \mathrm{~g} \mathrm{~mol}^{-1}\right)$. 


\section{Hydrogel fabrication}

Aqueous stock solutions of the two network-forming precursors - phenylboronic acid containing (PEG-PBA or PEG-APBA) and diol containing (PEG-GL or PEG-ND) - were prepared in the appropriate buffer $(0.1 \mathrm{M})$ and adjusted to the desired $\mathrm{pH}$ using $1 \mathrm{~m} \mathrm{HCl}$ or $1 \mathrm{~m} \mathrm{NaOH}$ (see Table $\mathbf{S 1}$ for the full list of buffers used). Buffers that are known to interact with boronic esters (such as phosphate, citrate, imidazole) were avoided. ${ }^{7}$ Equation S1 was used to calculate the volume of buffer, $V_{\text {buffer, }}$ and mass of polymer, $m_{\mathrm{PEG}}$, required to give the desired total polymer concentration, percent by weight (wt\%), in the final gel. Unless otherwise stated, the concentration of polymer in the networks was fixed at $10 \mathrm{wt} \%$ PEG. To fabricate the gels, equivalent volumes of the two stock solutions were combined and gelation occurred within $30 \mathrm{~s}$. Universal $\mathrm{pH}$ indicator was added to some of the gel samples to confirm that the correct $\mathrm{pH}$ value was maintained after gelation.

$V_{\text {buffer }}=\frac{m_{\mathrm{PEG}}}{(\mathrm{PEG} \mathrm{wt} \%) / 100 \%}-m_{\mathrm{PEG}}$

\begin{tabular}{|l|l|}
\hline Buffer composition (0.1 м) & pH \\
\hline acetic acid-acetate & 4.0 \\
& 4.5 \\
\hline MES & 5.0 \\
\hline HEPES & 5.5 \\
& 6.0 \\
\hline carbonate-bicarbonate & 7.0 \\
& 7.5 \\
& 8.0 \\
\hline sodium phosphate & 9.0 \\
& 9.5 \\
\hline NaOH-KCl & 10.0 \\
& 11.0 \\
\hline
\end{tabular}

Table S1 Different types of buffer were used to make the gels at different $\mathrm{pH}$. 


\section{Computational details and methods}

\subsection{Calculation of $\Delta_{\mathrm{r}} G^{0}$ using DFT}

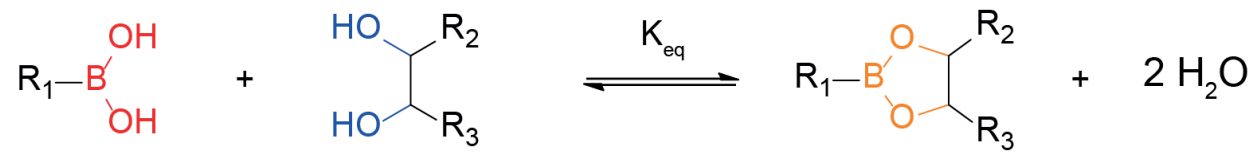

Scheme S1. Boronic acid (red) and diols (blue) can react to form boronic ester (orange) and water.

The free energies, $G$, for each of the species involved in boronic ester formation (Scheme S1) were calculated using DFT; $G$ values were subsequently used to determine the reaction Gibbs free energy, $\Delta_{\mathrm{r}} G^{0}$, (Equation S2) for the PEG-PBA/GL (Figure S1a) and the PEG-APBA/GL (Figure S1b) systems. Fructose was used as an analogue for GL because it was also used as an analogue for the determination of $K_{\text {eq }}$ in the fluorescence-based competitive displacement assay (see SI Section 5.3). Since hydration plays an important role in boronic ester chemistry, an implicit solvent (PCM) model was used to treat the interactions between water and the boronic acids/esters. ${ }^{4}$ This model was deemed sufficient, as treating water explicitly would probably affect the energies of all species similarly (error compensation in calculation of relative energies).

$\Delta_{\mathrm{r}} G^{0}=\left(G_{\text {ester }}+2 G_{\mathrm{H}_{2} \mathrm{O}}\right)-\left(G_{\text {acid }}+G_{\text {diol }}\right)$

a) PEG-PBA/GL system

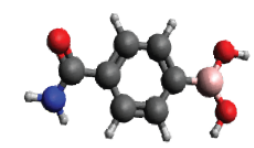

PBA

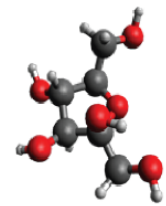

fructose

b) PEG-APBA/GL system

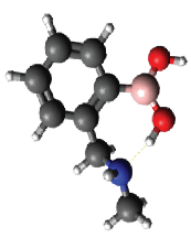

APBA

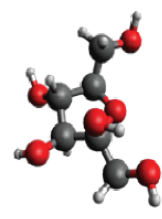

fructose

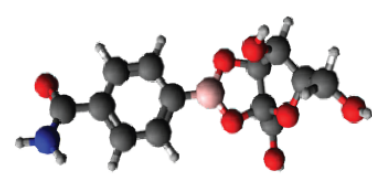

PBA-fructose ester

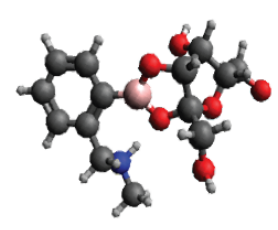

APBA-fructose ester

Figure S1. Optimized DFT structures for the $\Delta_{\mathrm{r}} \mathrm{G}^{0}$ calculations of (a) PEG-PBA/GL and (b) PEG-APBA/GL boronic ester formation. 


\subsection{Calculation of $\mathrm{p} K_{\mathrm{a} \text {,ester }}$ using DFT}

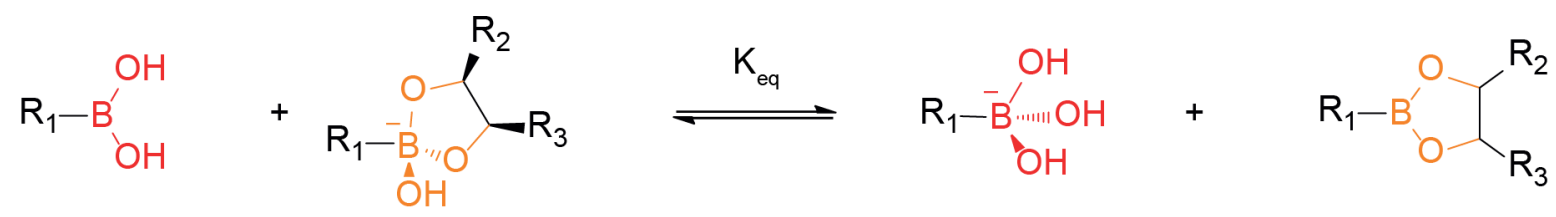

Scheme S2. Net reaction for the Lewis acid equilibria of a boronic acid and its corresponding boronic ester. Individual Lewis acid equilibria of both species are shown in Scheme $\mathbf{1 a}$ and $\mathbf{1 b}$ in the main text.

While direct calculation of absolute values of $\mathrm{p} K_{\mathrm{a}}$ using DFT is challenging, DFT was instead used to calculate $\Delta \mathrm{p} K_{\mathrm{a}}$ between boronic acids and their corresponding boronic esters, according to a previously established method. ${ }^{8}$ Here, the individual ionization equilibria for boronic acid/ester deprotonation (shown in Scheme 1a and 1b in the main text) were not considered; instead the free energy change for the net reaction, $\Delta_{\mathrm{r}} G^{0}$ net, was calculated (Scheme $\mathbf{S 2}$ and Equation S3). From there, $\mathrm{p} K_{\mathrm{a}, \text { ester }}$ for PEG-PBA/GL (Figure S2a) and PEG-APBA/GL (Figure S2b) were estimated from the calculated $\Delta_{\mathrm{r}} G^{0}$ net and the known values of $\mathrm{p} K_{\mathrm{a} \text {,acid }}$ (Equation S4).

$\Delta_{\mathrm{r}} G_{\text {net }}^{0}=\left(G_{\text {acid, anionic }}+G_{\text {ester, neutral }}\right)-\left(G_{\text {acid, neutral }}+G_{\text {ester, anionic }}\right)$

$\mathrm{p} K_{\mathrm{a}, \text { ester }}=\frac{\Delta_{\mathrm{r}} G_{\text {net }}^{0}}{\mathrm{RT} \ln (10)}+\mathrm{p} K_{\mathrm{a}, \text { acid }}$

a) PEG-PBA/GL system

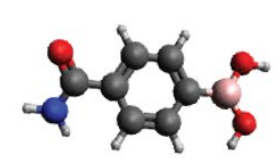

PBA (neutral)

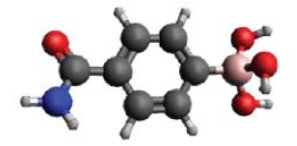

PBA (anionic)

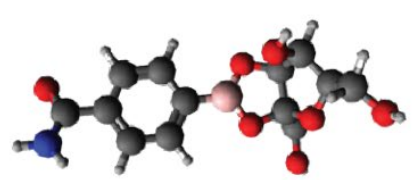

PBA-fructose ester (neutral)

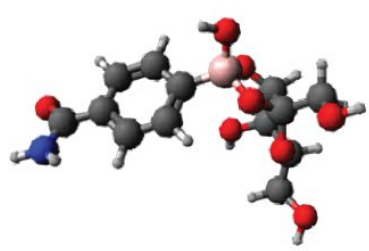

PBA-fructose ester (anionic)

b) PEG-APBA/GL system

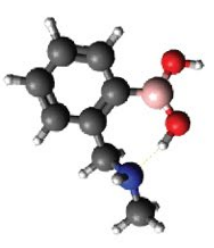

APBA (neutral)

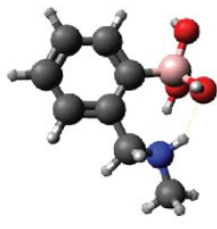

APBA (anionic)

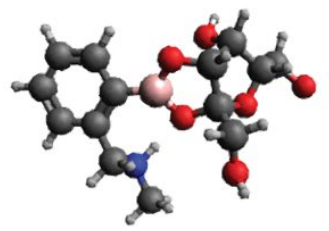

APBA-fructose ester (neutral)

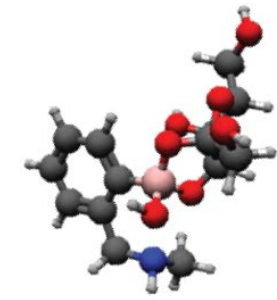

APBA-fructose ester (anionic)

Figure S2. Optimized DFT structures for the $\mathrm{p} K_{\mathrm{a}}$ determination of the (a) PEG-PBA/GL and (b) PEG-APBA/GL boronic ester. 
a) PBA-ARS equilibrium

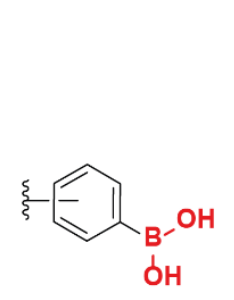

PBA

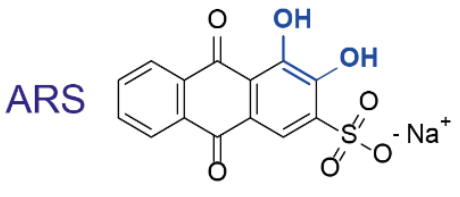

$\mathrm{K}_{\text {ARS }}$

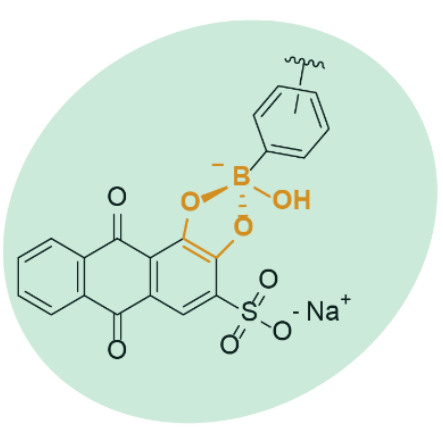

PBA-ARS adduct (575 $\mathrm{nm}$ emission)

b) Competitive displacement
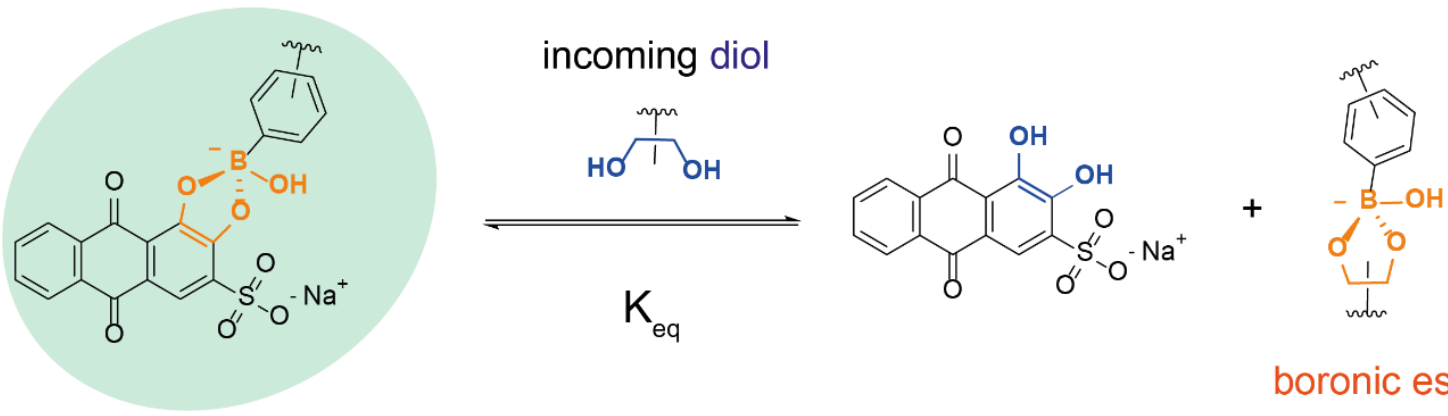

boronic ester

Figure S3. A three-component competitive displacement assay used to determine $K_{\text {eq }}$ for a PBA/diol pair, involving ARS, a diol-containing fluorescent reporter. (a) The PBA-ARS equilibrium $\left(K_{\mathrm{ARS}}\right)$ was first determined by titrating PBA into ARS and measuring the fluorescence increase due to the formation of the PBA-ARS adduct. (b) From there, $K_{\text {eq }}$ was determined by titrating the diol into the PBA/ARS solution and monitoring the decrease in fluorescence caused by the competitive displacement of the ARS by the diol.

The equilibrium constant $\left(K_{\mathrm{eq}}\right)$ between PBAs and diols were determined following previously published methods. ${ }^{9,10}$ In brief, a fluorescence-based competitive displacement assay was set up involving three components: a PBA derivative (linear PEG-PBA), a diol (fructose, as an analogue for GL), and Alizarin Red S (ARS) (a diol-containing fluorescent reporter; additionally served as the analogue for ND). $K_{\text {eq }}$ was determined at each pH by preparing all the required solutions in the appropriate buffer $(0.1 \mathrm{M}$; Table S1) and by measuring the $\mathrm{pH}$ of each solution before use. Representative plots used to determine $K_{\mathrm{ARS}}$ and $K_{\text {eq }}$ for PEG-PBA/GL and PEG-PBA/ND at each pH are shown in SI Section 7.6. Note that calculating $K_{\mathrm{ARS}}$ was sufficient to determine $K_{\mathrm{eq}}$ in the PEG-PBA/ND system, as ARS is structurally similar to ND and was therefore used as its analogue. To determine $K_{\text {eq }}$ for a particular PBA and diol pair, the equilibrium constant between PBA and ARS, $K_{\mathrm{ARS}}$, had to be first determined (Figure S3a). For this, different PBA concentrations, $[\mathrm{PBA}]$, up to $[\mathrm{PBA}]_{0}=2 \mathrm{~mm}$, were titrated into a solution of constant ARS concentration, $[\mathrm{ARS}]_{0}=$ $0.009 \mathrm{~mm}$. Formation of the PBA-ARS adduct lead to an increase in fluorescence intensity, $I_{\mathrm{f}}$, at $460 / 575 \mathrm{~nm}$. The background fluorescence intensity, $I_{\mathrm{b}}$, was measured when $[\mathrm{PBA}]=0 \mathrm{~mm}$ and subtracted. Thus, $1 /\left(I_{\mathrm{f}}-I_{\mathrm{b}}\right)$ versus $1 /[\mathrm{PBA}]$ 
was plotted and $K_{\mathrm{ARS}}$ was calculated by dividing the plot intercept by the slope, using the Benesi-Hildebrand method (Equation S5), where $k$ is a constant grouping various instrument and material parameters. ${ }^{10}$

$\frac{1}{I_{\mathrm{f}}-I_{\mathrm{b}}}=\frac{1}{k K_{\mathrm{ARS}}[\mathrm{PBA}]}+\frac{1}{k}$

Once $K_{\mathrm{ARS}}$ was calculated, $K_{\mathrm{eq}}$ was determined through a competitive binding assay where different concentrations of diol, [diol], were titrated into a solution containing $[\mathrm{PBA}]_{0}=2 \mathrm{~mm}$ and $[\mathrm{ARS}]_{0}=0.009 \mathrm{~mm}$. The starting $[\mathrm{diol}]_{0}$ that was needed depended on the strength of the PBA-diol interaction. The full list of [diol $]_{0}$ for each $\mathrm{pH}$ can be found in SI Section 7.6. Increasing [diol] displaced a fraction of the ARS from the PBA-ARS adduct, resulting in a decrease in $I_{\mathrm{f}}$ (Figure $\mathbf{S 3 b}$ ). The indicator ratio, $Q$, was then obtained by measuring the fluorescence intensity in the presence of a competitive diol, $I_{\mathrm{f}}$, diol, (at different [diol]) and the fluorescence intensity of the PBA-ARS adduct in the absence of competitive diol, If, PBA-ARs (Equation S6).

$Q=\frac{I_{\mathrm{f}, \text { PBA-ARS }}-I_{\mathrm{f}, \text { diol }}}{I_{\mathrm{f}, \text { diol }}-I_{\mathrm{b}}}$

Next, after defining the quantity $P$ (Equations S7), $K_{\text {eq }}$ was found from the plot of $[$ diol $] / P$ vs $Q$ by dividing the slope of the plot by the $K_{\mathrm{ARS}}$ found previously (Equation S8).

$P=[\mathrm{PBA}]_{0}-\frac{1}{Q K_{\mathrm{ARS}}}-\frac{[\mathrm{ARS}]_{0}}{1+Q}$

$\frac{[\mathrm{diol}]}{P}=\frac{K_{\mathrm{ARS}}}{K_{\mathrm{eq}}} Q+1$ 


\subsection{Determination of $K_{\text {eq }}$ using $1 \mathrm{D}^{1} \mathrm{H}$ NMR}

phenyl ring $(5 \mathrm{H})$<smiles>Cc1cccc(B(O)O)c1</smiles>

PBA $(7 \mathrm{H})$<smiles>OCC1O[C@](O)(CO)[C@@H](O)[C@@H]1O</smiles>

fructose $(12 \mathrm{H})$

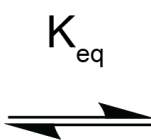

boronic ester $(15 \mathrm{H})$

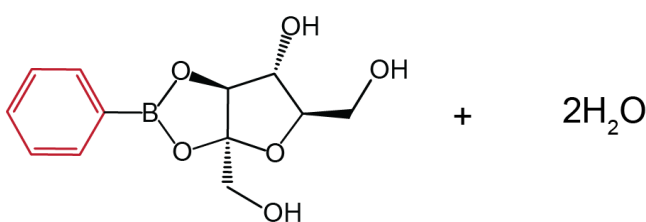

water $(4 \mathrm{H})$

Scheme S3. Boronic ester formation: phenylboronic acid (PBA) and fructose react to form boronic ester and water.

Consider the reaction that occurs when phenylboronic acid (PBA) and fructose are mixed together in solution, forming a boronic ester and water (Scheme S3). $K_{\mathrm{eq}}$ for this reaction is calculated from the relative concentrations of reactants and products at equilibrium (Equation S9), which can be determined through $1 \mathrm{D}{ }^{1} \mathrm{H}$ NMR.

$K_{\text {eq }}=\frac{[\text { ester }]\left[\mathrm{H}_{2} \mathrm{O}\right]^{2}}{[\mathrm{PBA}][\text { fructose }]}$

First, two precursor solutions were prepared, one containing PBA $(0.1 \mathrm{м})$ in $\left(\mathrm{CD}_{3}\right)_{2} \mathrm{SO}$ and one containing fructose $(0.1 \mathrm{M})$ in $\left(\mathrm{CD}_{3}\right)_{2} \mathrm{SO}$. Next, a third solution was prepared by mixing equimolar amounts of the PBA and fructose solutions, resulting in formation of boronic ester and water (Scheme S3). After letting the reaction reach equilibrium for $2 \mathrm{~h}, 1 \mathrm{D}{ }^{1} \mathrm{H}$ NMR experiments were setup for all three samples at $25^{\circ} \mathrm{C}$. Representative spectra for the PBA, fructose, and boronic ester solutions are shown in SI Section 7.7. To determine $K_{\text {eq }}$, we assumed that the concentration of phenyl rings in the solution, [ring], remained constant throughout the experiment, as the phenyl ring is present on both sides of the reaction (Scheme S3). Thus, $[\mathrm{ring}]=0.05 \mathrm{M}$, the initial concentration of PBA right after mixing. [PBA] and [fructose] at equilibrium were determined by comparing the relative number of protons found in the phenyl ring of the PBA, $\mathrm{H}_{\text {ring, } \mathrm{PBA}}$, to the relative total number of protons found in the phenyl rings of the PBA and the boronic ester, $\mathrm{H}_{\text {ring, }}$ total, $\left(\right.$ Equation S10). $\mathrm{H}_{\text {ring, } \mathrm{PBA}}=\left(\mathrm{HPBA}_{\mathrm{O}} \mathrm{OH} / 2\right)^{*} 5$, where $\mathrm{HPBA}_{\mathrm{O}}$ Он is the relative number of protons found in the hydroxyl groups of PBA. Likewise, [ester] was determined from the relative number of protons found in the phenyl ring of the boronic ester, $\mathrm{H}_{\text {ring, ester }}=\mathrm{H}_{\text {ring, total }}-\mathrm{H}_{\text {ring, PBA }}$ (Equation S11). Finally, $\left[\mathrm{H}_{2} \mathrm{O}\right]$ was found from the relative number of protons found in water, $\mathrm{H}_{\mathrm{H} 2 \mathrm{O}}$ (Equation S12). The relative number of protons were determined from Figure S19; $\mathrm{H}_{\text {ring, }}$ total was found by integrating the peaks from 7.3 to $7.8, \mathrm{H}_{\mathrm{PBA}}$, OH was found by integrating the peak at $8.02 \mathrm{ppm}$, and $\mathrm{H}_{\mathrm{H} 2 \mathrm{O}}$ was found by integrating the peak at $3.36 \mathrm{ppm}$. After three experiments, the average $K_{\text {eq }}$ was $277( \pm 37)$.

$[\mathrm{PBA}]=[$ fructose $]=[$ ring $] \frac{\mathrm{H}_{\text {ring, }} \text { PBA }}{\mathrm{H}_{\text {ring, total }}}$ 
[ester] $=[$ ring $] \frac{H_{\text {ring, ester }}}{H_{\text {ring, total }}}$

$\left[\mathrm{H}_{2} \mathrm{O}\right]=[$ ring $] \frac{\mathrm{H}_{\mathrm{H}_{2} \mathrm{O}}}{2}$ 


\subsection{Determination of $k_{\mathrm{f}}$ and $k_{\mathrm{b}}$ using $2 \mathrm{D}{ }^{1} \mathrm{H}$ NMR (EXSY)}

2D ${ }^{1} \mathrm{H}$ NMR exchange spectroscopy (EXSY) was used to estimate the forward and backward reaction rates, $k_{\mathrm{f}}$ and $k$ b, for boronic ester formation in neutral and basic conditions, according to previously established protocols with some modifications. ${ }^{11-13}$ A stock solution was prepared by mixing phenylboronic acid (PBA; $\left.50 \mathrm{mM}\right)$ and fructose (50 $\mathrm{mM}$ ) in distilled water. The $\mathrm{pH}$ of the samples was adjusted using the $\mathrm{pH}$ meter by adding $1 \mathrm{~m} \mathrm{NaOH}$. Water was subsequently removed by freeze-drying and the samples were re-dissolved in $\mathrm{D}_{2} \mathrm{O}$. In total, samples with $\mathrm{pH} 7,8$, and 9 were prepared. After allowing the samples to reach equilibrium for $2 \mathrm{~h}$, NOESY experiments were conducted at $25^{\circ} \mathrm{C}$ with varying mixing times, $\left(\tau_{\mathrm{m}}=1.0,2.0\right.$, and $\left.3.0 \mathrm{~s}\right)$. Here, the negative intensities generated by the NOESY sequence are due to the contributions from direct chemical exchange of protons. Thus, the relative intensities of the irradiated diagonal peaks and those of the cross-peaks between chemically exchanging species were used to calculate $k_{\mathrm{f}}{ }^{\prime}$ and $k_{\mathrm{b}}{ }^{\prime}$, the forward and backward magnetization exchange rate constants, which can be converted to $k_{\mathrm{f}}$ and $k_{\mathrm{b}}$, once the relative concentrations of the exchanging species are known. ${ }^{11,14}$

The chemical exchange between PBA (unbound) and the fructose-PBA ester (bound) was analyzed (Scheme S3). The diagonal and cross-peaks of the bound (7.4-7.5 ppm) and unbound (7.6-7.7 ppm) aromatic resonances of PBA were integrated (SI Section 7.8) and $k^{\prime}{ }^{\prime}$ was calculated using EXSYCalc, a free software developed by MestReNova. The reference intensities $\left(\tau_{\mathrm{m}}=0 \mathrm{~s}\right)$ were obtained directly from the $1 \mathrm{D}{ }^{1} \mathrm{H}$ NMR spectra. At $\mathrm{pH} 7$, the calculated rates were $k_{\mathrm{b}}{ }^{\prime}=0.096,0.10$, and $0.11 \mathrm{~s}^{-1}$ (for $\tau_{\mathrm{m}}=1.0,2.0$, and $3.0 \mathrm{~s}$, respectively) for an average rate of $0.10 \pm 0.0071 \mathrm{~s}^{-1}$. At $\mathrm{pH} 8$, the calculated rates were $k \mathrm{~b}^{\prime}=0.024,0.27$, and $0.28 \mathrm{~s}^{-1}$ (for $\tau_{\mathrm{m}}=1.0,2.0$, and $3.0 \mathrm{~s}$, respectively) for an average rate of $0.26 \pm 0.0021 \mathrm{~s}^{-1}$. At $\mathrm{pH} 9$, the calculated rates were $k \mathrm{~b}^{\prime}=0.0020,0.0030$, and $0.0050 \mathrm{~s}^{-1}$ (for $\tau_{\mathrm{m}}=1.0,2.0$, and $3.0 \mathrm{~s}$, respectively) for an average rate of $0.0033 \pm 0.0015 \mathrm{~s}^{-1}$. 


\subsection{Determination of $\Delta G^{*}, \Delta H_{b}{ }^{*}$, and $\Delta S_{\mathrm{b}}^{*}$ from shear rheometry}

The following method was developed to quantify the activation energies for dynamic covalent chemistries (in this case boronic esters) installed at the junctions of polymer networks directly from shear rheometry. The Eyring equation (Equation S13) is used in chemical kinetics to describe changes in the rate of a chemical reaction against temperature..$^{15}$

$k_{\mathrm{b}}=\frac{\kappa k_{\mathrm{B}} T}{h} \mathrm{e}^{\frac{\Delta S_{\mathrm{b}}^{\ddagger}}{R}} \mathrm{e}^{-\frac{\Delta H_{\mathrm{b}}^{\ddagger}}{R T}}$

Here, $k_{\mathrm{b}}$ is the backwards reaction rate constant, $T$ is the absolute temperature, $R$ is the gas constant, $h$ is Planck's constant, $k_{\mathrm{B}}$ is Boltzmann's constant, $\kappa$ is the transmission coefficient (assumed to be unity), and $\Delta G_{\mathrm{b}}^{\ddagger}, \Delta H_{\mathrm{b}^{\ddagger}}^{\ddagger}$, and $\Delta S_{\mathrm{b}}^{\ddagger}$ are the backwards Gibb's energy, enthalpy, and entropy of activation, respectively.

To determine $k_{\mathrm{b}}$ at different $T$, stress relaxation (RX) experiments were used to calculate the relaxation time, $\tau_{\mathrm{R}}$, of the networks as a function of $T$, by assuming that $k_{\mathrm{b}}=1 / \tau_{\mathrm{R}}$ (setting the constant of proportionality in Equation 4 in the main text to unity). While it is not always possible to directly equate the dissociation rate of a junction to its rate in the dilute small-molecule regime,${ }^{16}$ it is reasonable to assume that the association and dissociation rates of dynamic covalent cross-links are governed by the forward and reverse reaction rate constants of the small molecule binding pairs, $k_{\mathrm{f}}$ and $k_{\mathrm{b}}{ }^{13,17-19} \mathrm{RX}$ were performed in the range of $T=5-50{ }^{\circ} \mathrm{C}$, at $5{ }^{\circ} \mathrm{C}$ intervals (Figure 5a in the main text). A constant $\gamma$ was applied to the sample and held, while monitoring the decay of $\sigma$ over time, $t$, by measuring the relaxation modulus, $G(t)$, whose rate of decay from an initial modulus, $G_{\mathrm{o}}$, is dependent on $\tau_{\mathrm{R}}$ (Equation S14). A frequency sweep (FS) was used as an alternative method to determine $\tau_{\mathrm{R}}$, as a complement to the $\mathrm{RX}$ measurements, where the crossover frequency $\omega_{\mathrm{c}}=1 / \tau_{\mathrm{R}}=k_{\mathrm{b}}($ Figure 1d in the main text $)$. Both methods were found to be equivalent, yielding similar activation energies (SI Section 7.9 for direct comparison).

$$
G(t)=G_{\mathrm{o}} \mathrm{e}^{-\frac{t}{\tau_{\mathrm{R}}}}
$$

Once $k_{\mathrm{b}}$ as a function of $T$ was determined, Eyring plots were constructed by plotting $\ln \left(k_{\mathrm{b}} / \mathrm{T}\right)$ against $1 / T$, and $\Delta H_{\mathrm{b}}{ }^{\ddagger}$ and $\Delta S_{\mathrm{b}}^{\ddagger}$ were obtained from the slope and the intercept of the plots, respectively (Figure $\mathbf{5 b}$ in the main text and Equation S13). $\Delta G_{\mathrm{b}}{ }^{*}$ was subsequently calculated according to Equation 6 in the main text. 


\section{Description of models}

\subsection{Maxwell model of linear viscoelasticity}

During dynamic mechanical analysis, the frequency-dependent complex modulus $G^{*}$ of the networks can be expressed in terms of the storage modulus $G^{\prime}(\omega)$ - a measure of the stored elastic energy in the material, and the loss modulus $G^{\prime \prime}(\omega)$ - a representation of the viscous energy dissipation by the material. Here, $\omega$ is the angular frequency of the applied cyclic strain. Equations $\mathbf{S 1 5}$ and $\mathbf{S 1 6}$ respectively define $G^{\prime}(\omega)$ and $G^{\prime \prime}(\omega)$.

$G^{\prime}(\omega)=G_{\mathrm{p}} \frac{\omega^{2} \tau_{\mathrm{R}}^{2}}{\omega^{2} \tau_{\mathrm{R}}^{2}+1}$

$G^{\prime \prime}(\omega)=G_{\mathrm{p}} \frac{\omega \tau_{\mathrm{R}}}{\omega^{2} \tau_{\mathrm{R}}^{2}+1}$

At low frequencies, the viscoelastic moduli of the gels scaled as $G^{\prime}(\omega) \sim \omega^{2}$ and $G^{\prime \prime}(\omega) \sim \omega^{1}$ (Figure 1d in the main text). These are the classic scaling rules for terminal relaxation in the single element Maxwell model of linear viscoelasticity, which combines in series an elastic element (spring) characterized by an instantaneous plateau shear modulus, $G_{\mathrm{p}}$, and a viscous element (dashpot) with a relaxation time constant, $\tau_{\mathrm{R}}=1 / \omega_{\mathrm{c}} \cdot{ }^{20,21}$ Here, $\omega_{\mathrm{c}}$ is the crossover frequency that occurs when $G^{\prime}(\omega)=G^{\prime \prime}(\omega)$ and represents the transition between purely viscoelastic behavior - when probed at fast time-scales - and when these materials flow as viscous liquids - when probed at long timescales. Therefore, tuning the frequency of the applied strain enables investigation of different timescales or relaxation modes within the materials.

\subsection{Dynamic-modified phantom network model}

According to the theory of rubber elasticity for cross-linked polymer networks, an entropic penalty is caused by deforming individual polymer chains away from their relaxed state, leading to a restoring force of $R T$ per mole of network strand, where $R$ is the gas constant and $T$ is the temperature. ${ }^{20}$ Thus, the shear modulus, $G$, of a network is directly related to the concentration of elastically active network strands, $v$, such that $G_{\mathrm{p}, \text { affine }}=v R T$. This affine approach assumes that each network strand experiences the same deformation as the bulk material. To account for the fact that the cross-links are not fixed in space but fluctuate around an average location, the phantom network model corrects $G$ by subtracting the total concentration of cross-links, $\mu$, from the concentration of elastically active network strands, $v$ (Equation S17) $^{22}$.

$G_{\mathrm{p}, \text { phantom }}=(\nu-\mu) R T$ 
Both $\mu$ and $v$ are calculated according to the Macosko-Miller recursive method. ${ }^{23}$ We consider an ideal network formed through the step-wise polymerization of two different types of tetra-functional polymeric macromers (A and B). Each type of functional group can only react to its complementary group (A and B react together), with no intramolecular reactions allowed. Assuming that A and B are present in equal amounts, the conversion of functional groups, or the reaction efficiency, $p$, is the same for both groups $\left(p_{\mathrm{A}}=p_{\mathrm{B}}=p\right)$. Equation S18 then gives the probability, $P_{\text {out }}$, that one of the four arms of the polymeric star leads to a 'finite' or dangling chain. When $P_{\text {out }}=1$, the network is unable to form; therefore, the critical conversion required to form a network is $p_{\mathrm{c}}=1 / 3 \cdot{ }^{17,22}$

$P_{\text {out }}=\left(\frac{1}{p}-\frac{3}{4}\right)^{\frac{1}{2}}-\frac{1}{2}$

In a network formed from tetra-functional macromers, only macromers that have three or four connections to the 'infinite' network are considered elastically active-acting as cross-links; macromers with only one or two connections are considered elastically inactive - acting either as dangling ends, loops or bridging chains. ${ }^{17}$ The probabilities that a macromer has three, $P 3$, or four, $P 4$, connections to the 'infinite' network are shown respectively in Equations S19 and S20. ${ }^{22}$

$$
\begin{aligned}
& P_{3}=4 P_{\text {out }}\left[1-P_{\text {out }}\right]^{3} \\
& P_{4}=\left[1-P_{\text {out }}\right]^{4}
\end{aligned}
$$

Thus, the total concentration of cross-links, $\mu$, is given by the sum of the elastically active macromers $\left(P_{3}\right.$ and $P_{4}$ ) multiplied by the total molar concentration of macromers [PEG] (Equation S21), as each elastically active macromer star is counted as one cross-link. The concentration of elastically active network strands, $v$, is given by a weighted sum of $P_{3}$ and $P_{4}$ (Equation S22), because macromers with 4 connections contribute 2 elastically active network strands while macromers with 3 connections on average contribute 1.5 elastically active network strands. ${ }^{17}$

$\mu=[\mathrm{PEG}]\left(\mathrm{P}_{3}+\mathrm{P}_{4}\right)$

$v=[\mathrm{PEG}]\left(\frac{3}{2} \mathrm{P}_{3}+2 \mathrm{P}_{4}\right)$

Finally, we considered the dynamic nature of the junctions that link the network strands. In DCvNs, the reacted bonds are not permanent, but break and reform continually. Thus, gelation and the cross-link density in DCvNs depend not only on the concentration of functional groups, $c$, as in permanent covalent networks, but also on the equilibrium constant, $K_{\text {eq. }}$. Note that for networks formed from tetra-functional macromers $(f=4), c=f[\mathrm{PEG}] / 2=2[\mathrm{PEG}]$, as we assume that the two network components are present in equal amounts. Therefore, at sufficiently long times after mixing, 
when the system has reached thermodynamic equilibrium, the number of formed bonds or conversion of functional groups, $p$, can be calculated from $c$ and $K_{\text {eq }}\left(\right.$ Equation S23) ${ }^{6,17}$

$p=\left(1+\frac{1}{2 c K_{\mathrm{eq}}}\right)-\left[\left(1+\frac{1}{2 c K_{\mathrm{eq}}}\right)^{2}-1\right]^{\frac{1}{2}}$

In this way, we see that $G_{\mathrm{p}}$ in DCVNs is not just dependent on the polymer content, [PEG], but that it is also a function of $K_{\text {eq. }}$. We can now define the conditions to form a percolated and stable network $\left(p>p_{\mathrm{c}}\right)$; namely that $K_{\mathrm{eq}} c \geq$ $3 / 4\left(\right.$ or $\left.[\mathrm{PEG}] K_{\mathrm{eq}} \geq 3 / 8\right)$. For $[\mathrm{PEG}]=0.01 \mathrm{м}\left(10 \mathrm{wt} \% \mathrm{PEG} ; M_{\mathrm{n}} \approx 10000 \mathrm{~g} \mathrm{~mol}^{-1}\right), K_{\mathrm{eq}} \geq 37.5 \mathrm{M}^{-1}$.

This analysis treats the dynamic phantom network model for the DCvNs investigated here, which are formed from tetra-functional macromers. In general, the model can be extended to any functionality with the same logic that combines statistical theories of network behavior and an understanding of the chemical equilibrium. 


\section{Supplementary figures}

\subsection{Strain recovery}

a) 2 cycles

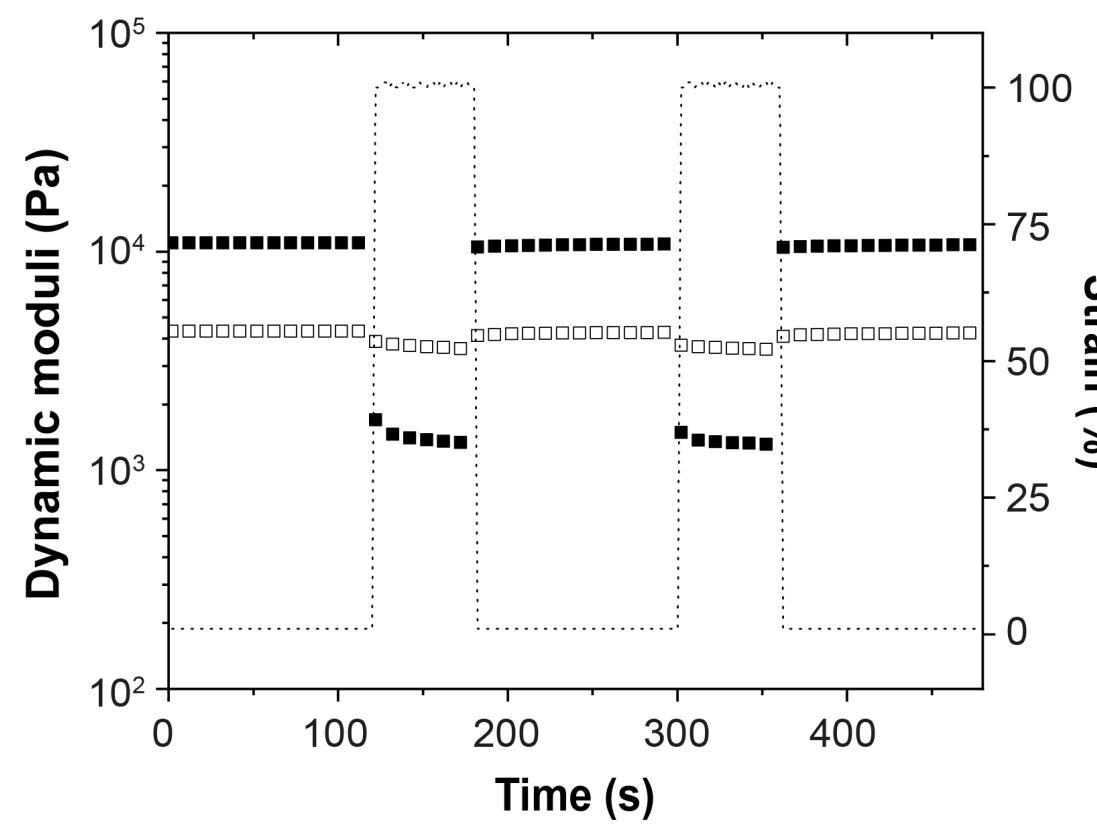

b) 10 cycles

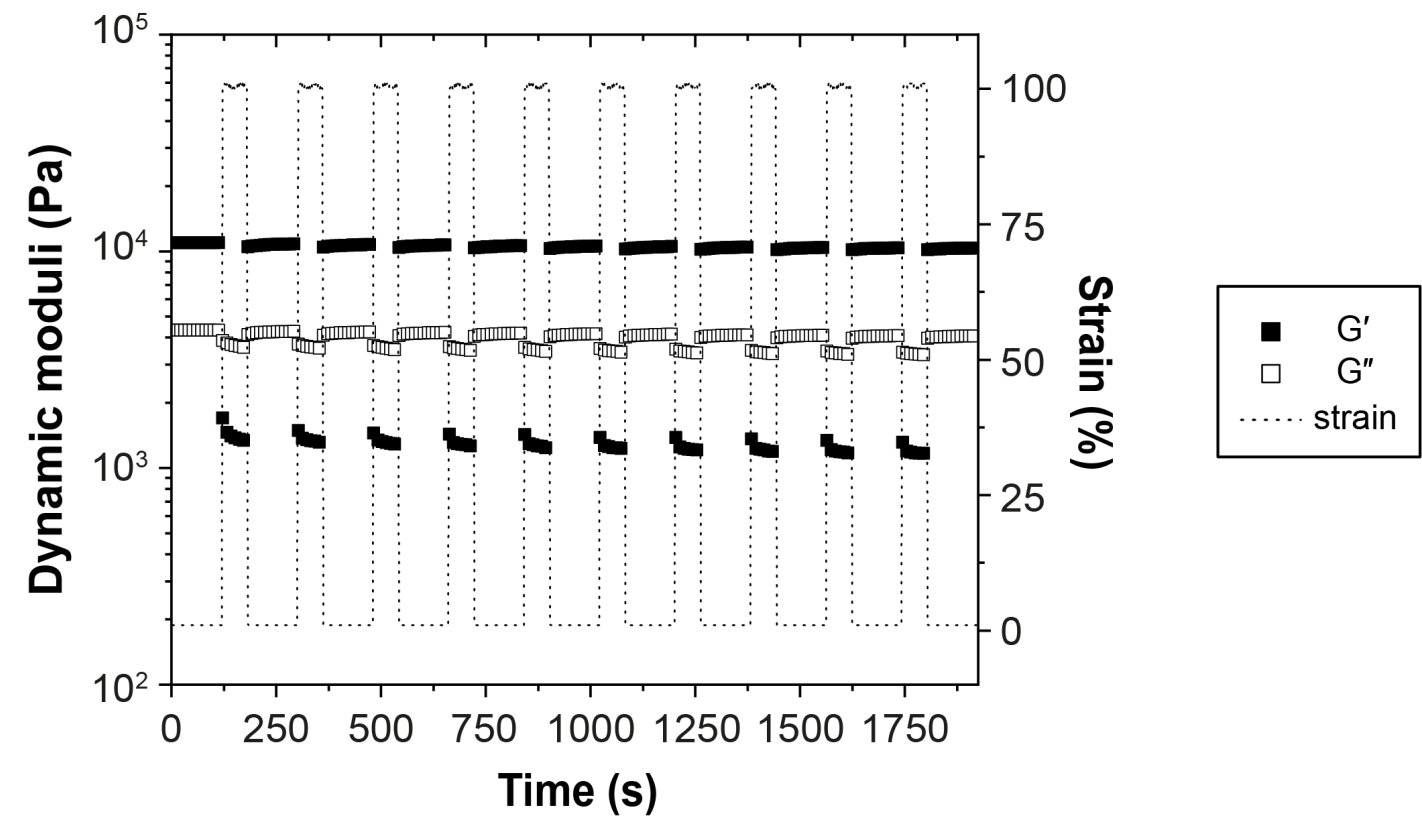

Figure S4. The self-healing behavior of the gels was confirmed via strain recovery experiments, by monitoring the storage and loss moduli, $G^{\prime}$ and $G^{\prime \prime}$, during alternating periods of high strain $(\gamma=100 \%)$ and low strain $(\gamma=$ $1 \%$ ). (a) 2 cycles and (b) 10 cycles are shown for a representative boronic ester-based hydrogel (PEG-PBA/GL, $10 \mathrm{wt} \%$, pH $\left.7.5 ; \omega=10 \operatorname{rad~s}^{-1}\right)$. 


\section{a) Complete gelation}

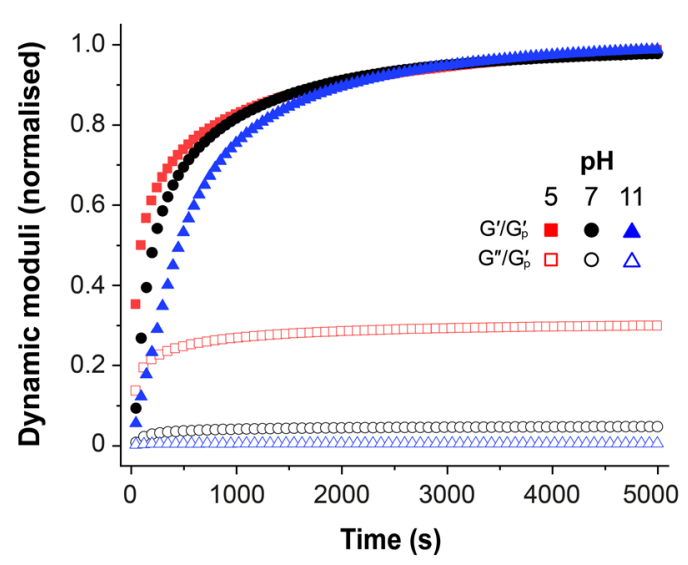

b) Partial gelation

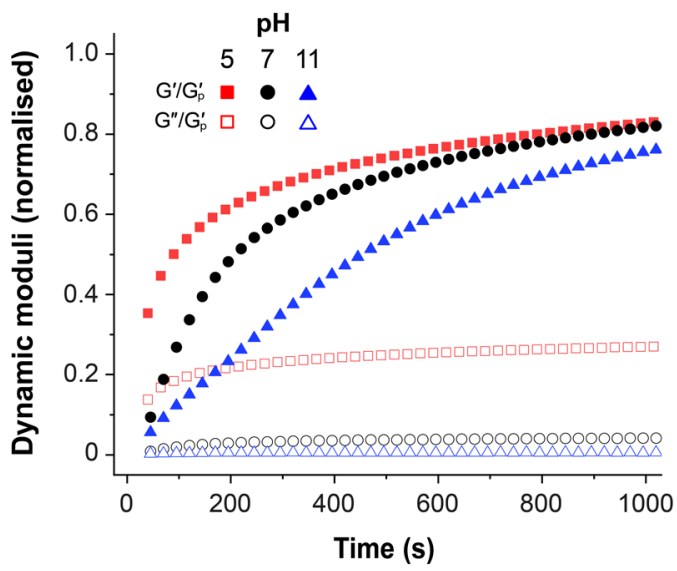

Figure S5. The gelation time of the boronic ester-based hydrogels at different $\mathrm{pH}$ was characterized using time sweep experiments (TS). Right after mixing the precursors on the rheometer plate, the storage modulus, $G^{\prime}$, and the loss modulus, $G^{\prime \prime}$, were monitored over time and normalized to the storage plateau modulus, $G_{\mathrm{p}}^{\prime}$, of the sample. (a) Complete gelation was achieved after $5000 \mathrm{~s}$ at all pH (PEG-APBA/GL, $10 \mathrm{wt} \% ; \gamma=1 \%$; $\omega=10 \mathrm{rad} \mathrm{s}^{-1}$ ). (b) The rate of increase of $G^{\prime}$ over time decreased with increasing $\mathrm{pH}$. 


\subsection{Constant of proportionality}

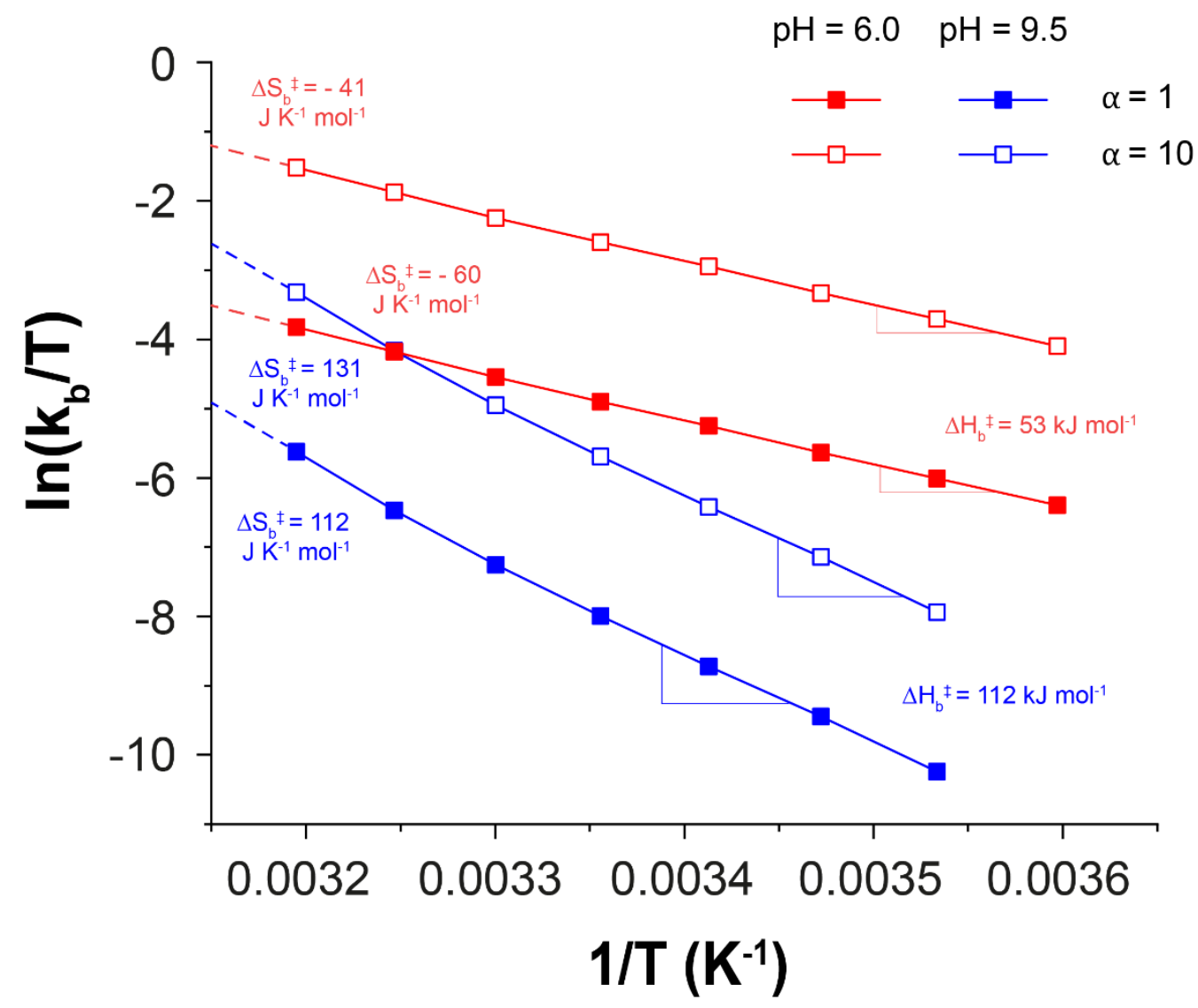

Figure S6. The relaxation time, $\tau_{\mathrm{R}}$, is inversely related to the backwards reaction rate constant, $k \mathrm{~b},\left(\tau_{\mathrm{R}}=\alpha / k_{\mathrm{b}}\right.$; Equation 4 in the main text). In the main text, Eyring plots were constructed from rheological measurements by setting the constant of proportionality, $\alpha$, to unity and assuming that network rearrangement $\left(\tau_{R}\right)$ was on the same timescale as the lifetime of the bond, $\tau_{\mathrm{B}}$. However, the dynamics of the network relative to the lifetime of the bond can be scaled by setting different values of $\alpha$. Therefore, we compared the behavior of networks (PEG-APBA/GL, $10 \mathrm{wt} \% ; \gamma=1 \%)$ at different $\mathrm{pH}$, when $\tau_{\mathrm{R}}=\tau_{\mathrm{B}}(\alpha=1)$ and when $\tau_{\mathrm{R}}=10 \tau_{\mathrm{B}}(\alpha=10)$. For $\alpha=1$, the backwards activation Gibbs free energy, $\Delta G_{\mathrm{b}}^{\ddagger}$ was found to be 71.0 and $78.5 \mathrm{~kJ} \mathrm{~mol}^{-1}$ at $\mathrm{pH} 6$ and 9.5 , respectively. For $\alpha=$ $10, \Delta G_{\mathrm{b}}^{\ddagger}$ was found to be 65.2 and $72.8 \mathrm{~kJ} \mathrm{~mol}^{-1}$ at $\mathrm{pH} 6$ and 9.5 , respectively. Therefore, while the absolute magnitudes of $\Delta G_{\mathrm{b}}^{\ddagger}$ vary with $\alpha$, the relative values between different $\mathrm{pH}$ stay the same, allowing us to draw meaningful conclusions from the trends (assuming that $\alpha$ is constant with $\mathrm{pH}$ ). Furthermore, the trends for the activation entropy, $\Delta S_{\mathrm{b}^{\ddagger}}^{\ddagger}$, and enthalpy, $\Delta H_{\mathrm{b}}^{\ddagger}$, did not change significantly. In fact, when varying $\alpha$, assuming that it is independent of temperature, $\Delta H_{b}{ }^{\ddagger}$ stays constant throughout. On the other hand, large changes in $\alpha$ did not significantly alter $\Delta S_{\mathrm{b}}^{\ddagger}$. At $\mathrm{pH} 6, \Delta S_{\mathrm{b}}^{\ddagger}$ varied from -60 to $-41 \mathrm{~J} \mathrm{~K}^{-1} \mathrm{~mol}^{-1}$ while at $\mathrm{pH} 9.5 \Delta S_{\mathrm{b}^{\ddagger}}^{\ddagger}$ varied from 112 to $131 \mathrm{~J} \mathrm{~K}^{-1} \mathrm{~mol}^{-1}$. Thus, our main conclusions (whether $\Delta \mathrm{Sb}^{\ddagger}$ is negative or positive) were not affected by $\alpha$. As a whole, the trends in the activation energies were not significantly altered by $\alpha$, only the absolute magnitudes. 


\subsection{Activation energies of PEG-PBA/ND and PEG-APBA/ND}

a) Network stability

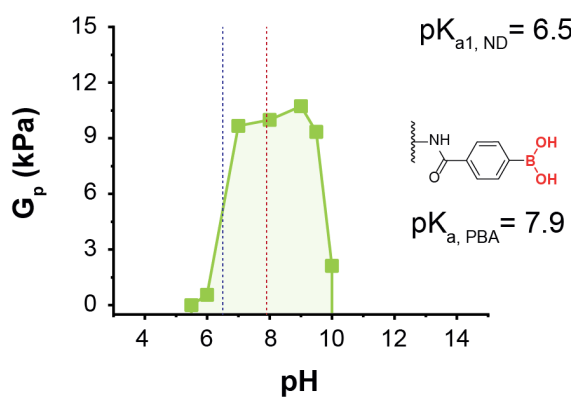

c) Activation entropy

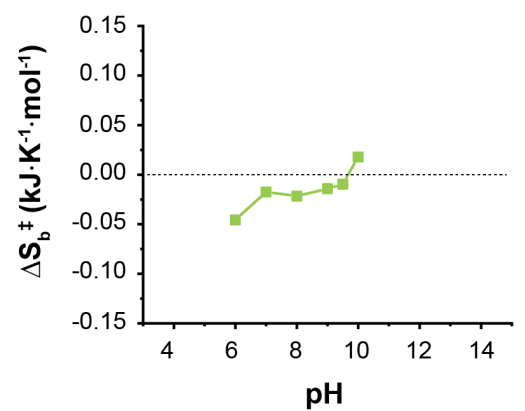

b) Network dynamics

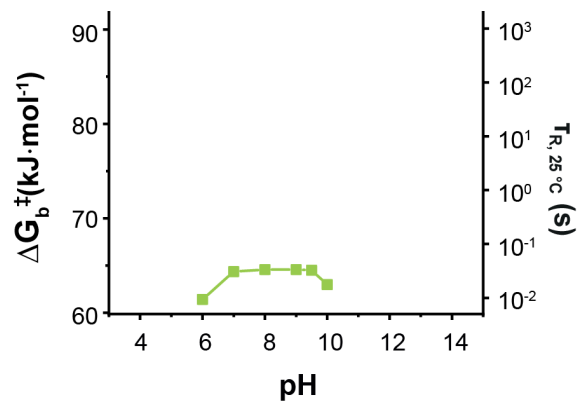

d) Activation enthalpy

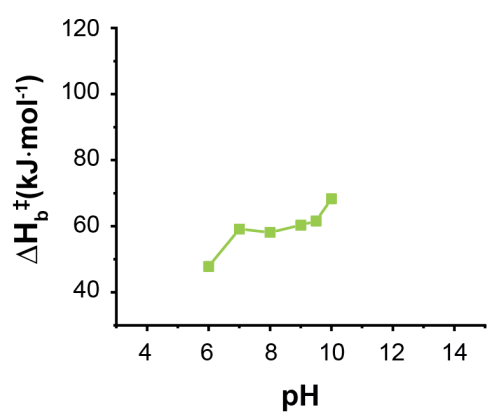

Figure S7. (a) The network stability, $G_{\mathrm{p}}$, and (b) the network dynamics, $\tau_{\mathrm{R}}$, of the PEG-PBA/ND system were characterized via shear rheometry at different $\mathrm{pH}(10 \mathrm{wt} \% ; \gamma=1 \%)$. (c) Activation entropies (d) and enthalpies were subsequently obtained from Eyring plots of $\tau_{\mathrm{R}}$ as a function of temperature.

a) Network stability

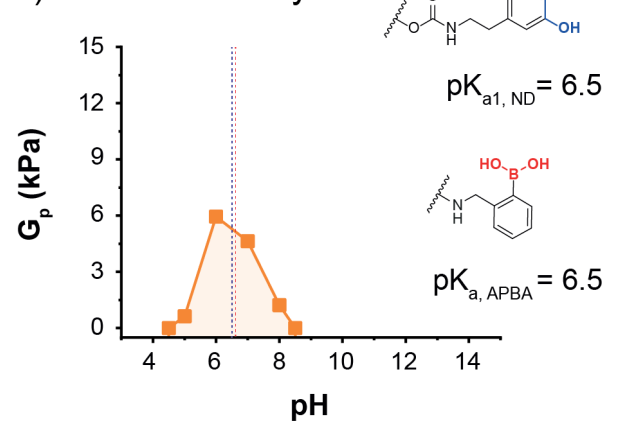

c) Activation entropy

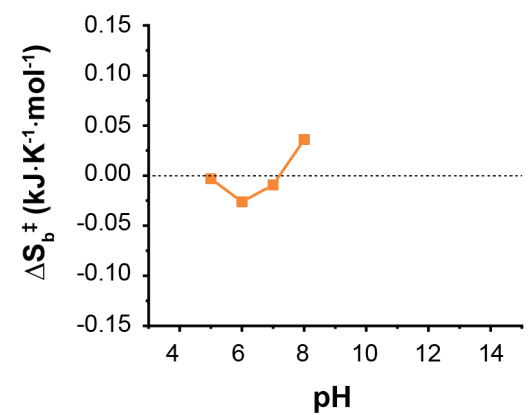

\section{b) Network dynamics}

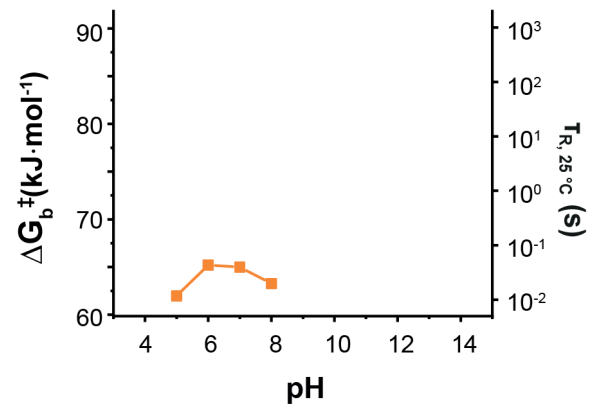

d) Activation enthalpy

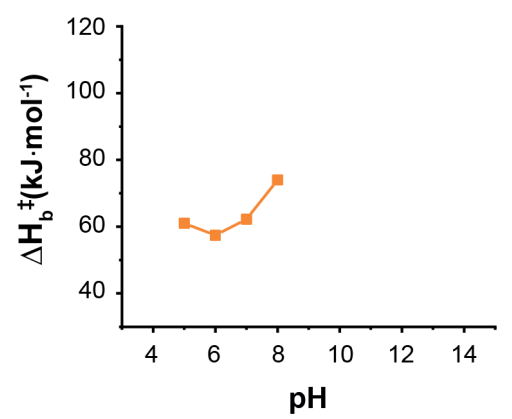

Figure S8. (a) The network stability, $G_{\mathrm{p}}$, and (b) the network dynamics, $\tau_{\mathrm{R}}$, of the PEG-APBA/ND system were characterized via shear rheometry at different $\mathrm{pH}(10 \mathrm{wt} \% ; \gamma=1 \%)$. (c) Activation entropies (d) and enthalpies were subsequently obtained from Eyring plots of $\tau_{\mathrm{R}}$ as a function of temperature. 
7.5. 1D ${ }^{1} \mathrm{H}$ NMR Spectra (Synthesis)

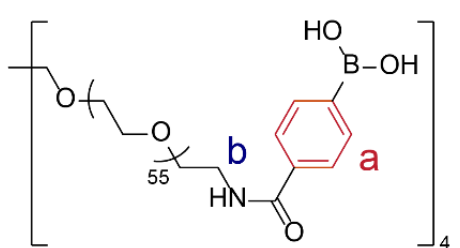

4-arm PEG-PBA (10 kDa)
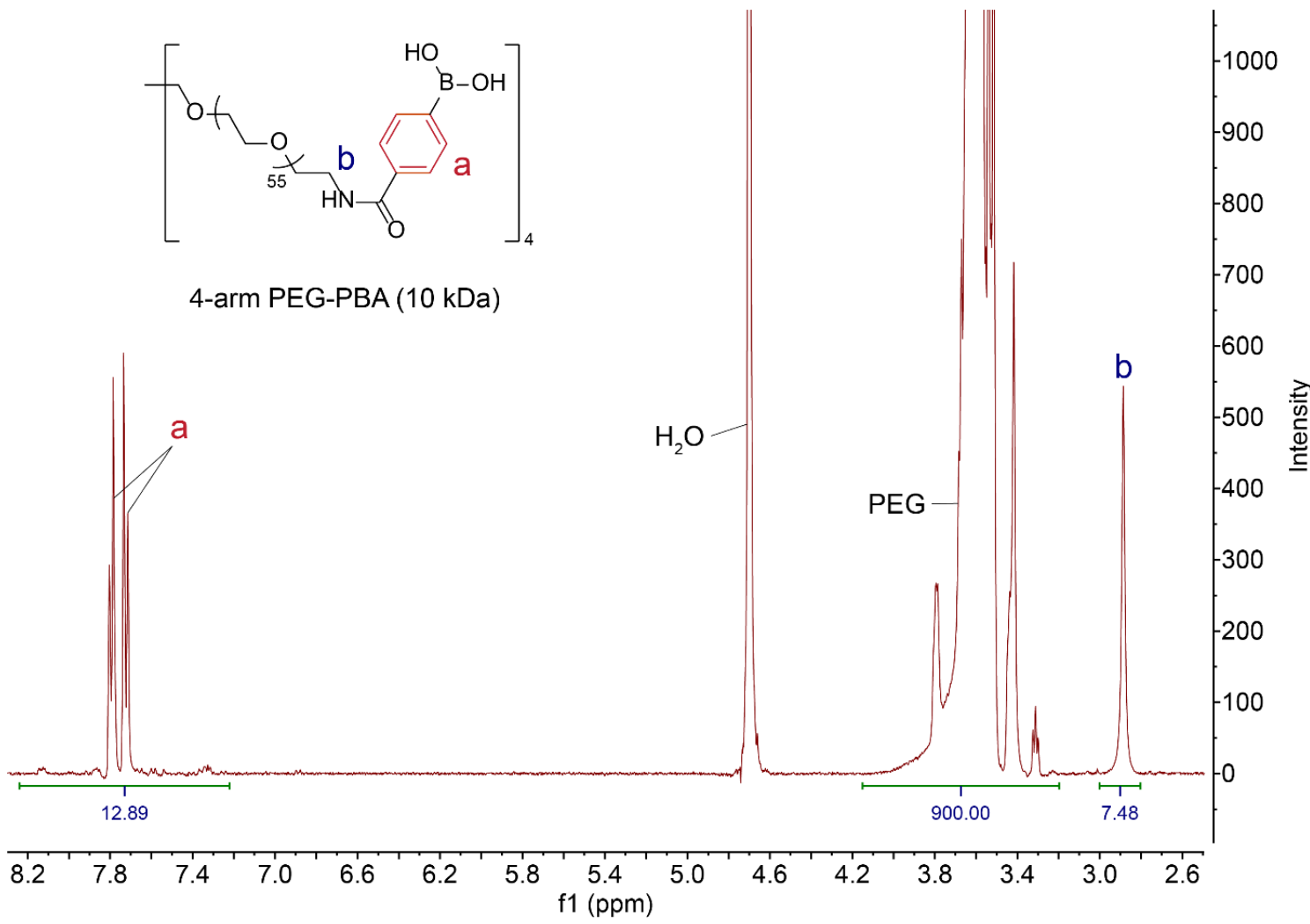

Figure S9. ${ }^{1} \mathrm{H}$ NMR spectrum of 4-arm PEG-PBA $\left(10 \mathrm{kDa} ; 400 \mathrm{MHz}, \mathrm{D}_{2} \mathrm{O}\right) . \approx 80 \%$ functionalization.<smiles>CCOCCOCCNCc1ccccc1B(O)O</smiles>

4-arm PEG-APBA (10 kDa)

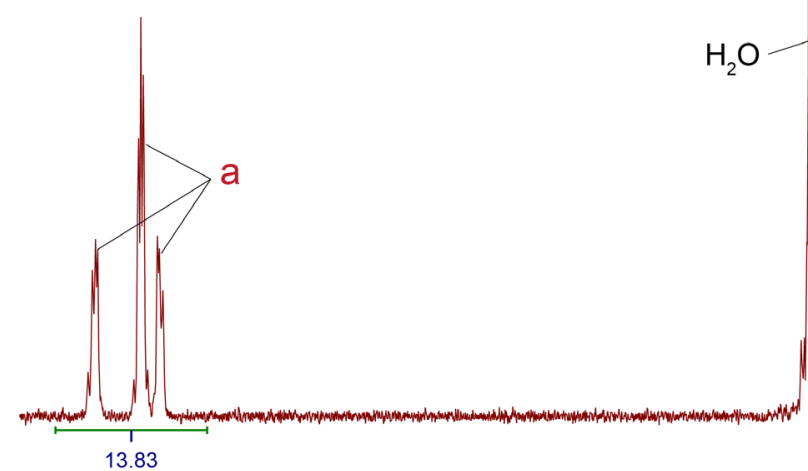

$5.5 \begin{gathered}5.0 \\ f 1(\mathrm{ppm})\end{gathered}$

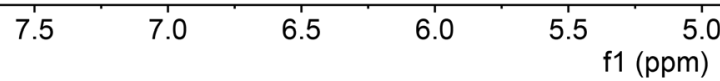

$-300$

$-250$

$-200$

150

$\frac{7}{0}$
$\frac{5}{9}$
$\stackrel{2}{\leq}$

Figure S10. ${ }^{1} \mathrm{H}$ NMR spectrum of 4 -arm PEG-APBA $\left(10 \mathrm{kDa} ; 400 \mathrm{MHz}, \mathrm{D}_{2} \mathrm{O}\right) . \approx 85 \%$ functionalization. 


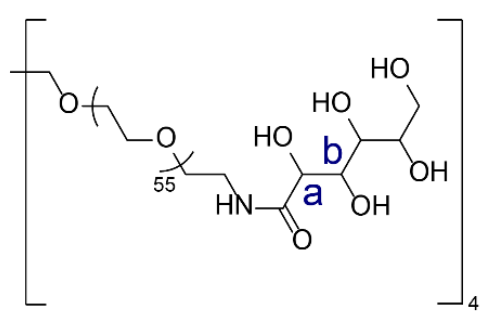

4-arm PEG-GL (10 kDa)

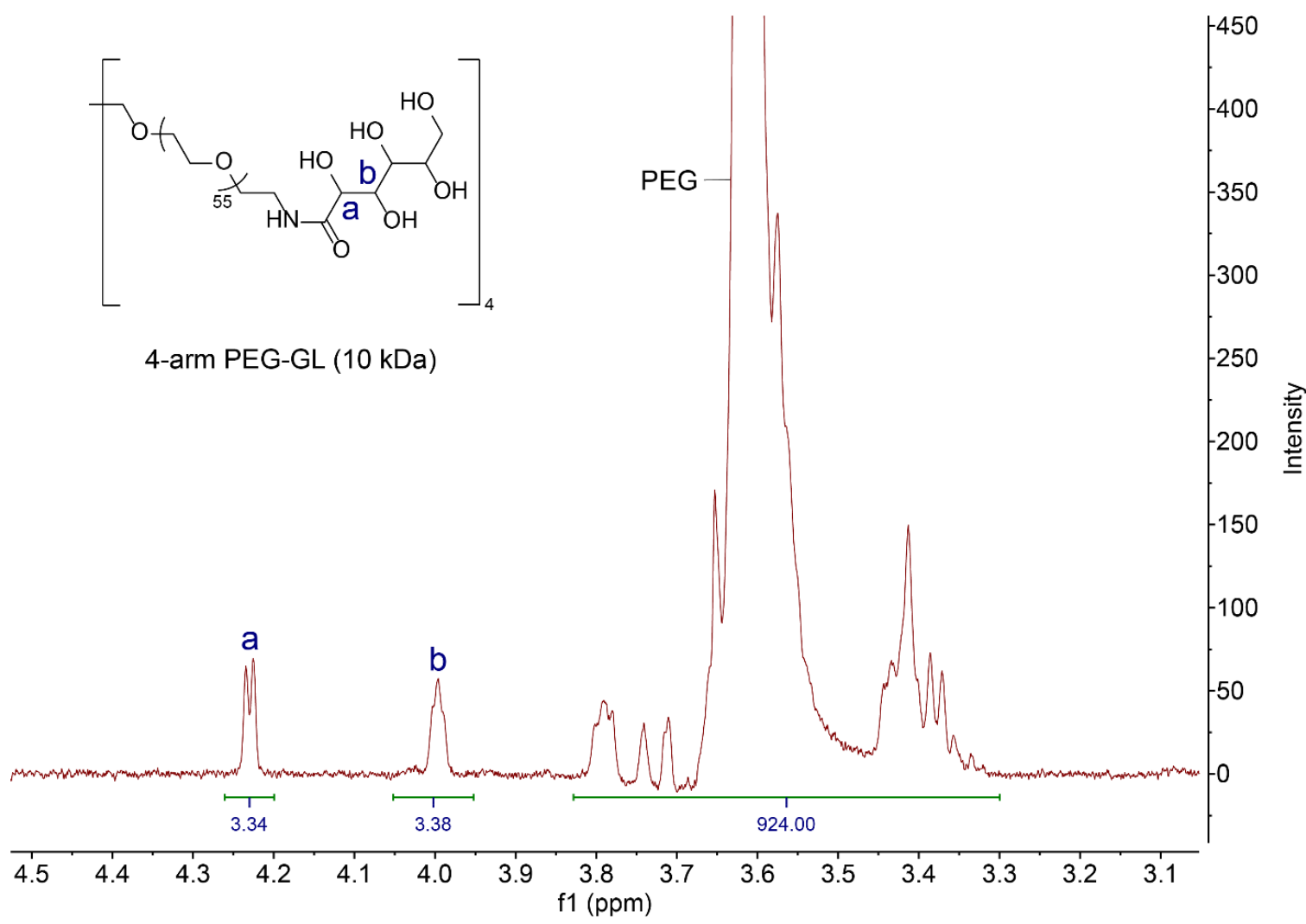

Figure S11. ${ }^{1} \mathrm{H}$ NMR spectrum of 4-arm PEG-GL $\left(10 \mathrm{kDa} ; 400 \mathrm{MHz}, \mathrm{D}_{2} \mathrm{O}\right) . \approx 85 \%$ functionalization.

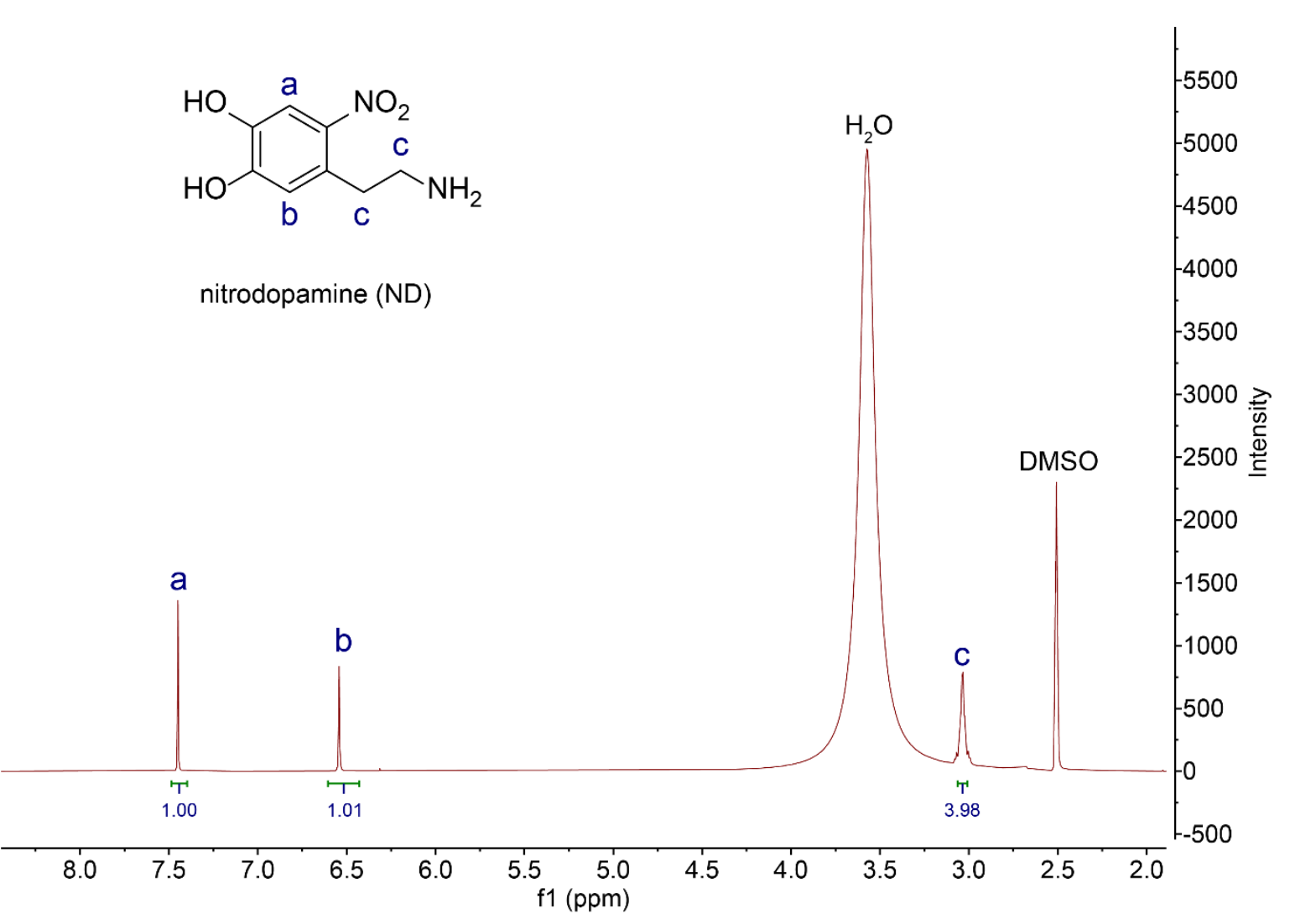

nitrodopamine (ND)

Figure S12. ${ }^{1} \mathrm{H}$ NMR spectrum of nitrodopamine (ND; $\left.400 \mathrm{MHz}, \mathrm{D}_{2} \mathrm{O}\right)$. 
<smiles>[2H]c1cc(O)c(O)cc1C(=O)NC(=O)OCCOCCOC(C)C</smiles>

4-arm PEG-ND (10 kDa)
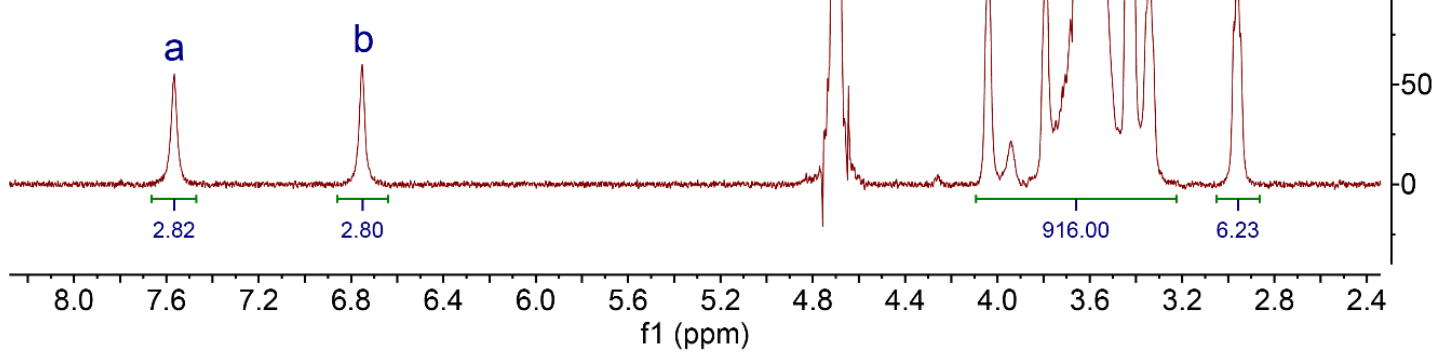

$-400$

$-350$

$-300$

$-250$

$-200$

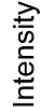

$-150$

$-100$

50

Figure S13. ${ }^{1} \mathrm{H}$ NMR spectrum of 4-arm PEG-ND $\left(10 \mathrm{kDa} ; 400 \mathrm{MHz}, \mathrm{D}_{2} \mathrm{O}\right) . \approx 70-75 \%$ functionalization.<smiles>COC(C)CCOCCNC(=O)c1ccc(B(O)O)cc1</smiles>

methoxy-PEG-PBA (10 kDa)
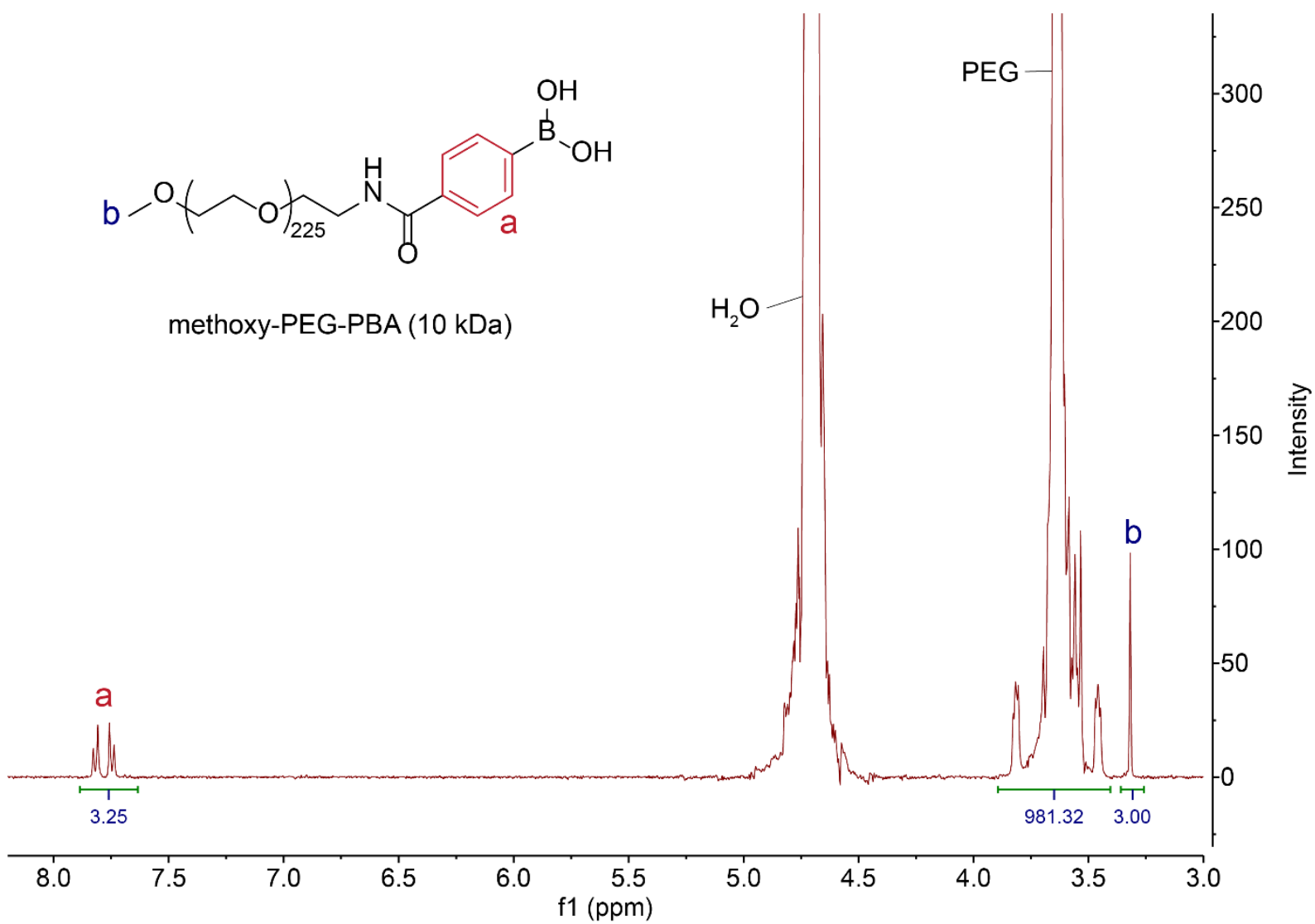

Figure S14. ${ }^{1} \mathrm{H}$ NMR spectrum of methoxy-PEG-PBA $\left(10 \mathrm{kDa} ; 400 \mathrm{MHz}, \mathrm{D}_{2} \mathrm{O}\right) . \approx 80 \%$ functionalization. 
7.6. Titration curves ( $K_{\text {ARS }}$ and $K_{\text {eq }}$ determination)

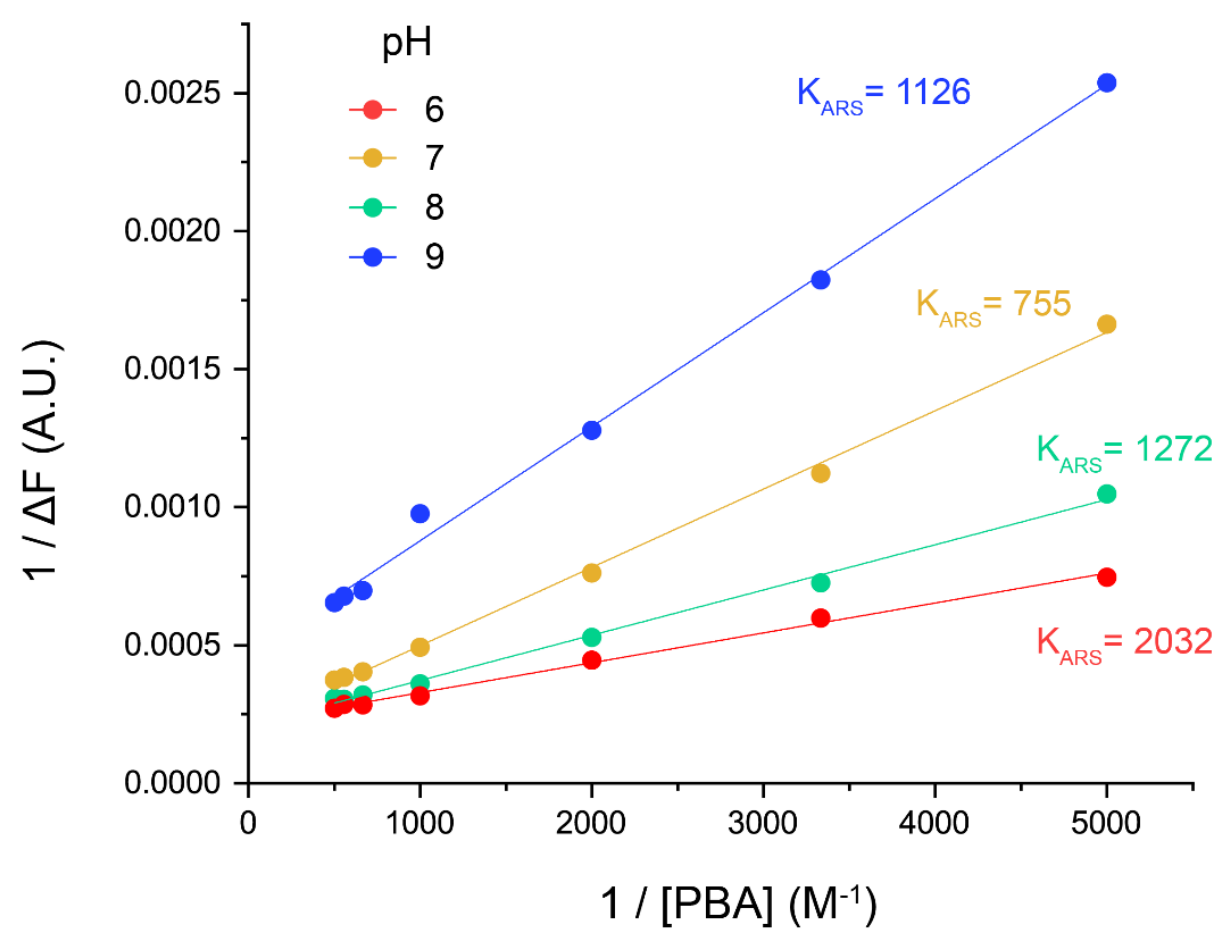

Figure S15. Representative titration curves to determine $K_{\mathrm{ARS}}$ of $\mathrm{PBA}$ at $\mathrm{pH}=6,7,8$, and 9. Concentrations of ARS remained constant throughout: $[\mathrm{ARS}]_{0}=0.009 \mathrm{~mm}$. The starting PBA concentration, $[\mathrm{PBA}]_{0}$, was $2 \mathrm{~mm}$. 


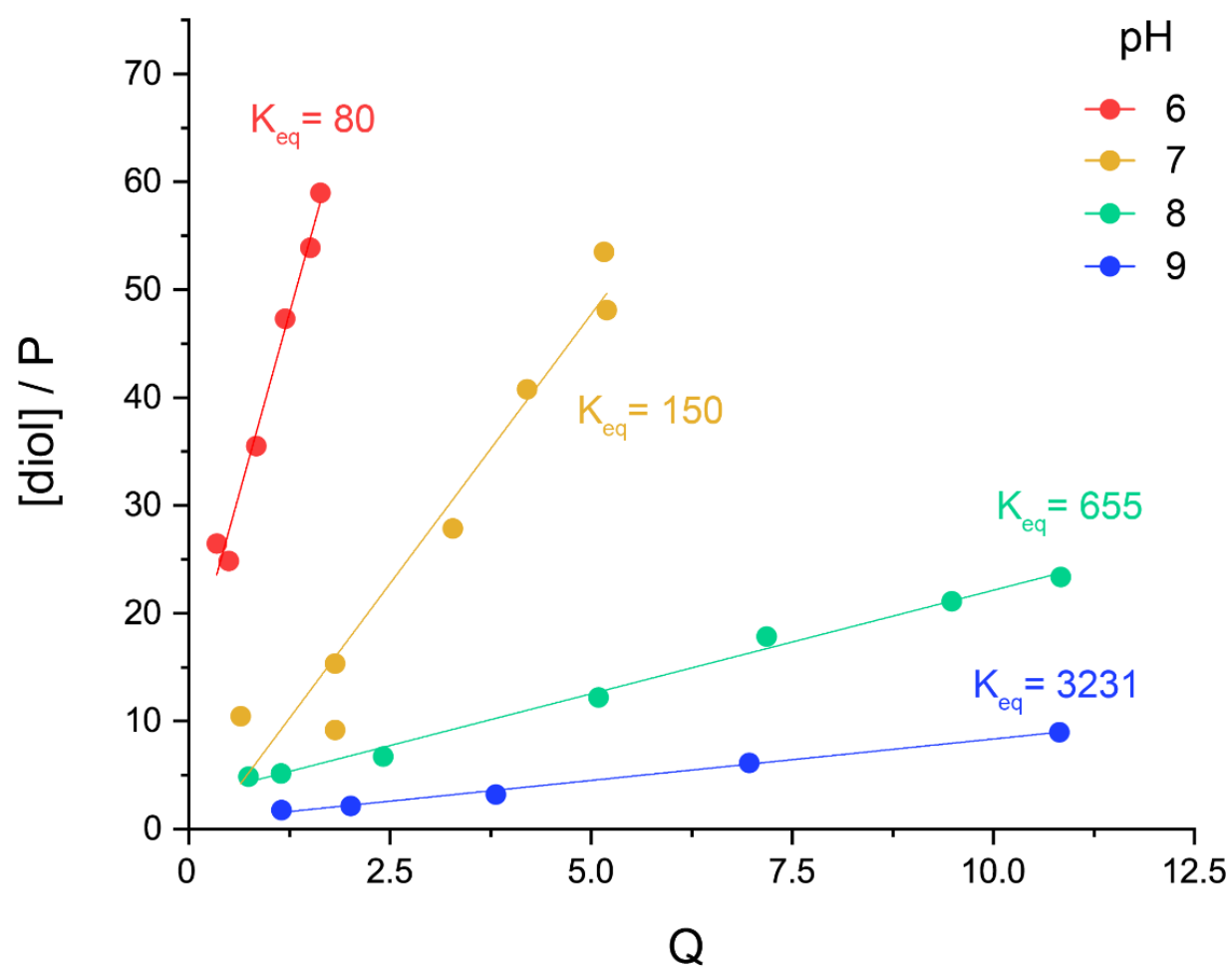

Figure S16. Representative titration curves to determine $K_{\text {eq }}$ of PBA and fructose. Concentrations of PBA and ARS remained constant throughout: $[\mathrm{PBA}]_{0}=2 \mathrm{mM}$ and $[\mathrm{ARS}]_{0}=0.009 \mathrm{mM}$. The starting diol concentrations, [diol $]_{0}$, were $540 \mathrm{~mm}$ at $\mathrm{pH} 6,100 \mathrm{~mm}$ at $\mathrm{pH} 7,45 \mathrm{~mm}$ at $\mathrm{pH} 8$, and $10 \mathrm{~mm}$ at $\mathrm{pH} 9$. 
7.7. $1 \mathrm{D}^{1} \mathrm{H}$ NMR Spectra $\left(K_{\text {eq }}\right.$ determination)

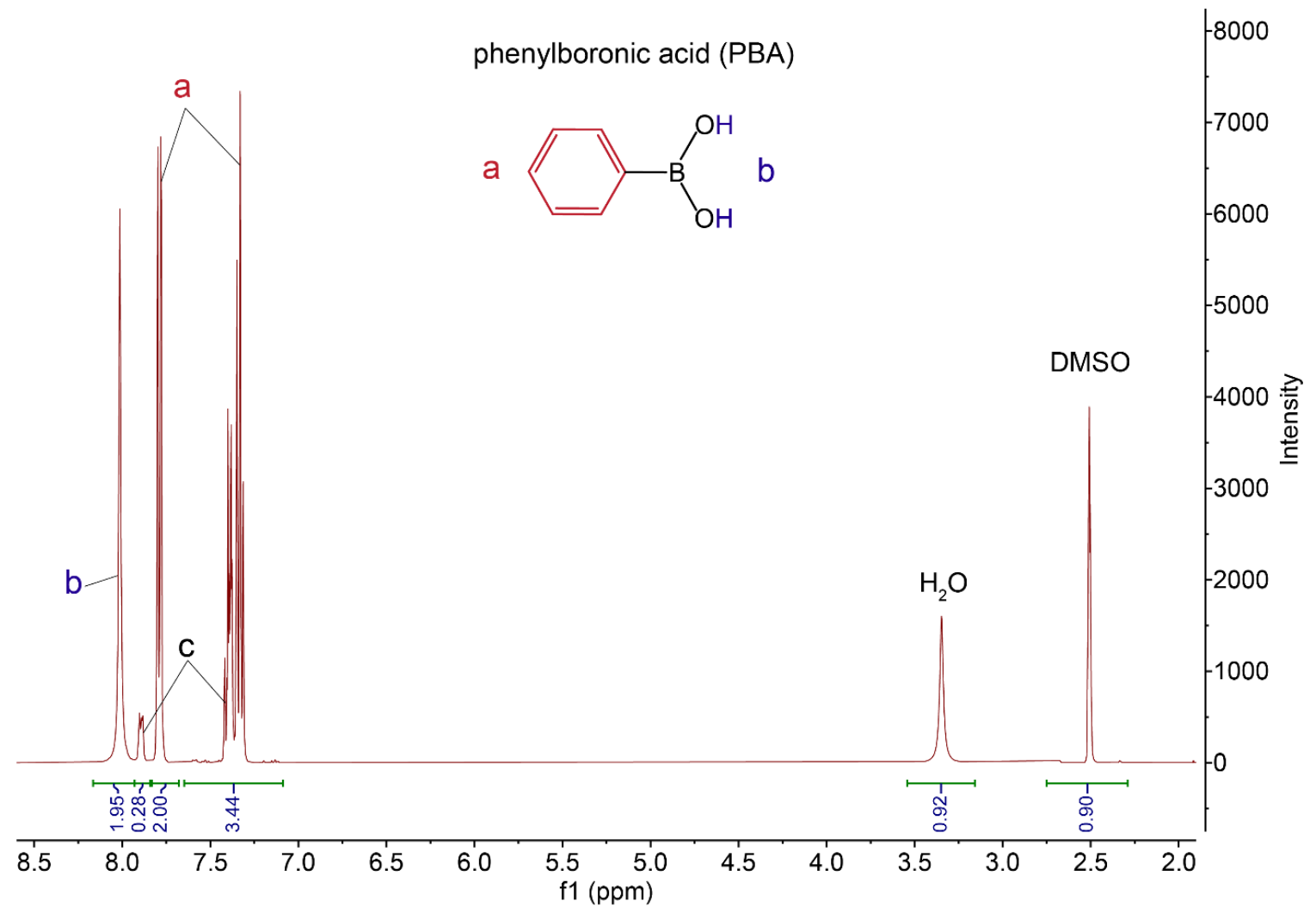

Figure S17. ${ }^{1} \mathrm{H}$ NMR spectrum of phenylboronic acid (PBA; $\left.0.1 \mathrm{M} ; 400 \mathrm{MHz},\left(\mathrm{CD}_{3}\right)_{2} \mathrm{SO}\right)$. Around $15 \%$ of the PBA is present in its anhydride form (boroxine; peak c).

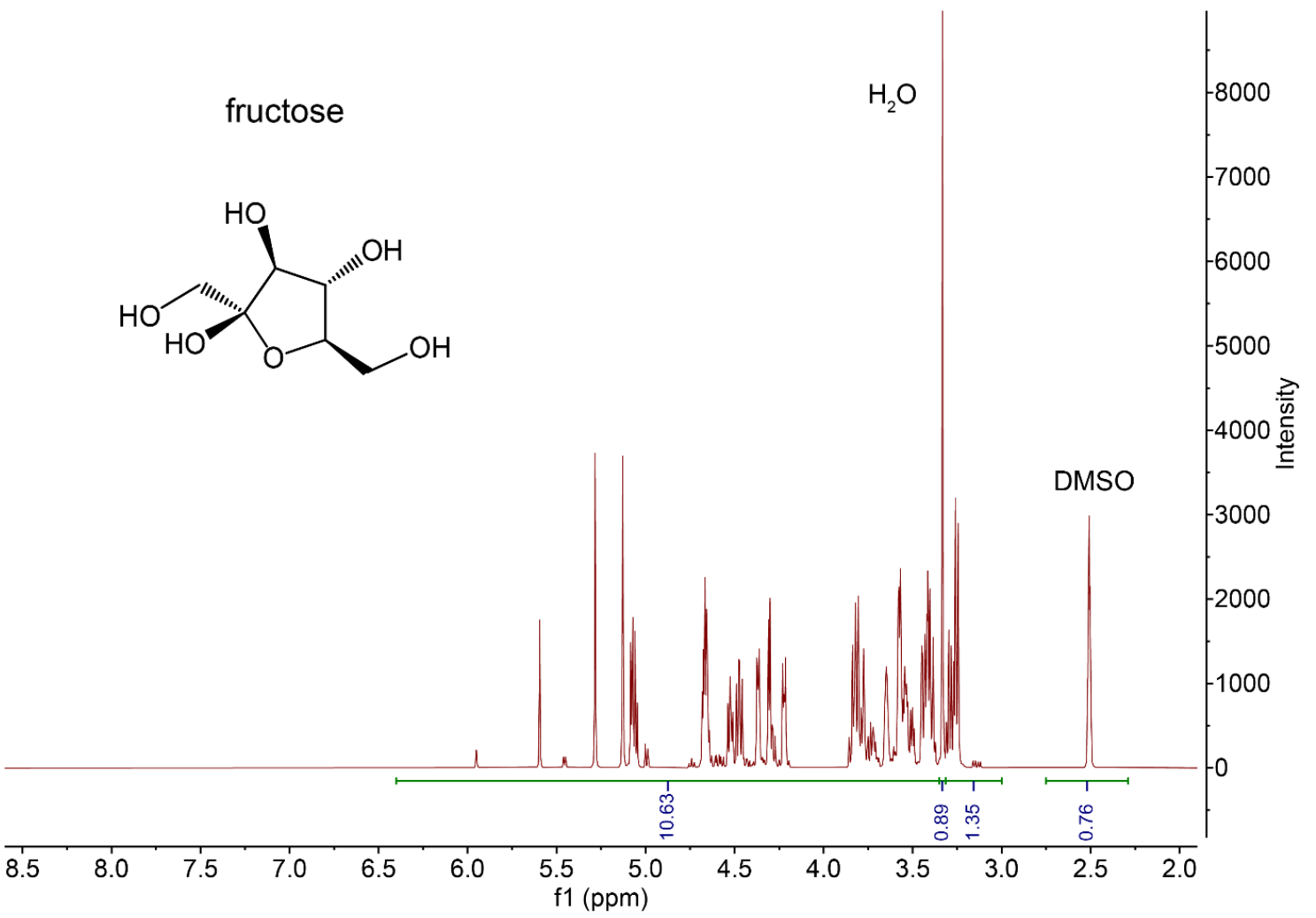

Figure S18. ${ }^{1} \mathrm{H}$ NMR spectrum of fructose $\left(0.1 \mathrm{M} ; 400 \mathrm{MHz},\left(\mathrm{CD}_{3}\right)_{2} \mathrm{SO}\right)$. 
a<smiles>OB(O)c1ccccc1</smiles>

PBA

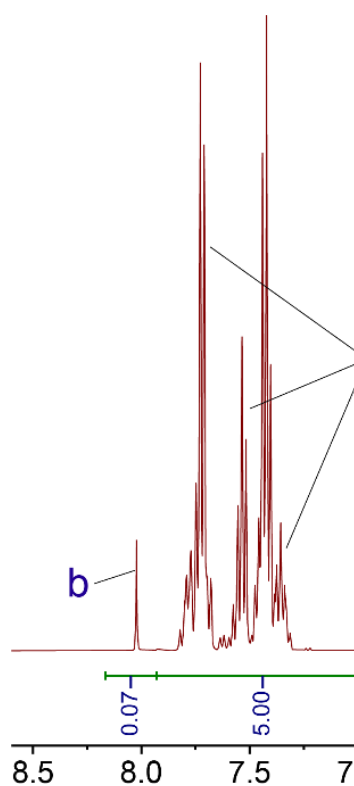

a<smiles>OC[C@H]1O[C@@]2(CO)OB(c3ccccc3)O[C@H]2[C@H]1O</smiles>

boronic ester

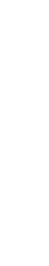

$\mathrm{H}_{2} \mathrm{O}$

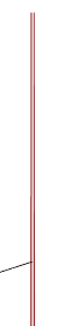

Figure S19. ${ }^{1} \mathrm{H}$ NMR spectrum of PBA and fructose mixed in equimolar amounts (initially $\left.0.05 \mathrm{M} ; 400 \mathrm{MHz},\left(\mathrm{CD}_{3}\right)_{2} \mathrm{SO}\right)$, forming boronic ester and water. 


\section{8. $2 \mathrm{D}{ }^{1} \mathrm{H}$ NMR Spectra (EXSY)}

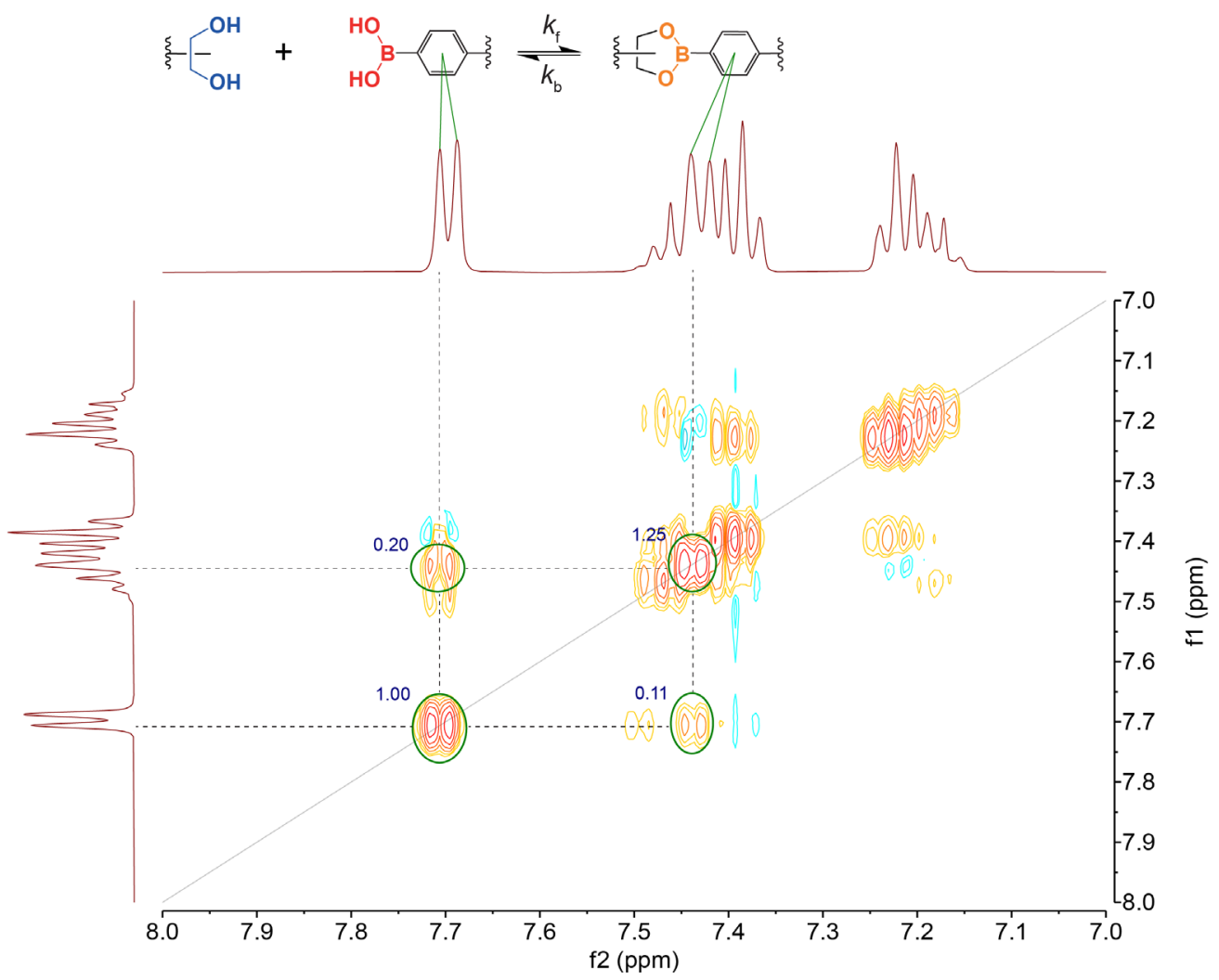

Figure S20. Representative 2D ${ }^{1} \mathrm{H}$ NMR spectrum of PBA $(25 \mathrm{mM})$ and fructose $(25 \mathrm{mM})$ mixed at $\mathrm{pH}$ 7, forming a boronic ester $\left(400 \mathrm{MHz}, \mathrm{D}_{2} \mathrm{O}\right.$; NOESY pulse sequence, $\left.\tau_{\mathrm{m}}=1.0 \mathrm{~s}\right)$.

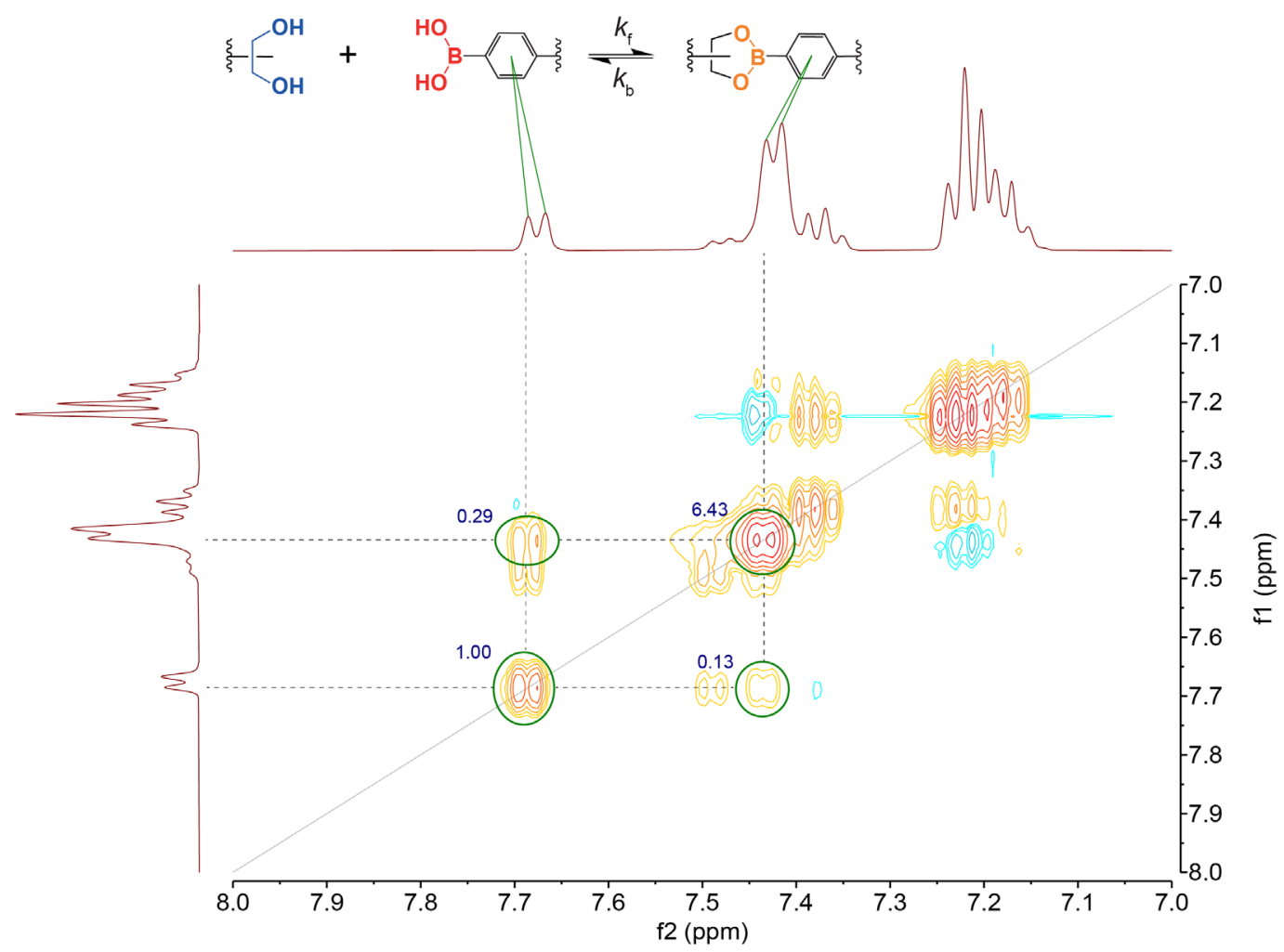

Figure S21. Representative 2D ${ }^{1} \mathrm{H}$ NMR spectrum of PBA $(25 \mathrm{mM})$ and fructose $(25 \mathrm{mM})$ mixed at pH 8 , forming a boronic ester $\left(400 \mathrm{MHz}, \mathrm{D}_{2} \mathrm{O}\right.$; NOESY pulse sequence, $\left.\tau_{\mathrm{m}}=1.0 \mathrm{~s}\right)$. 


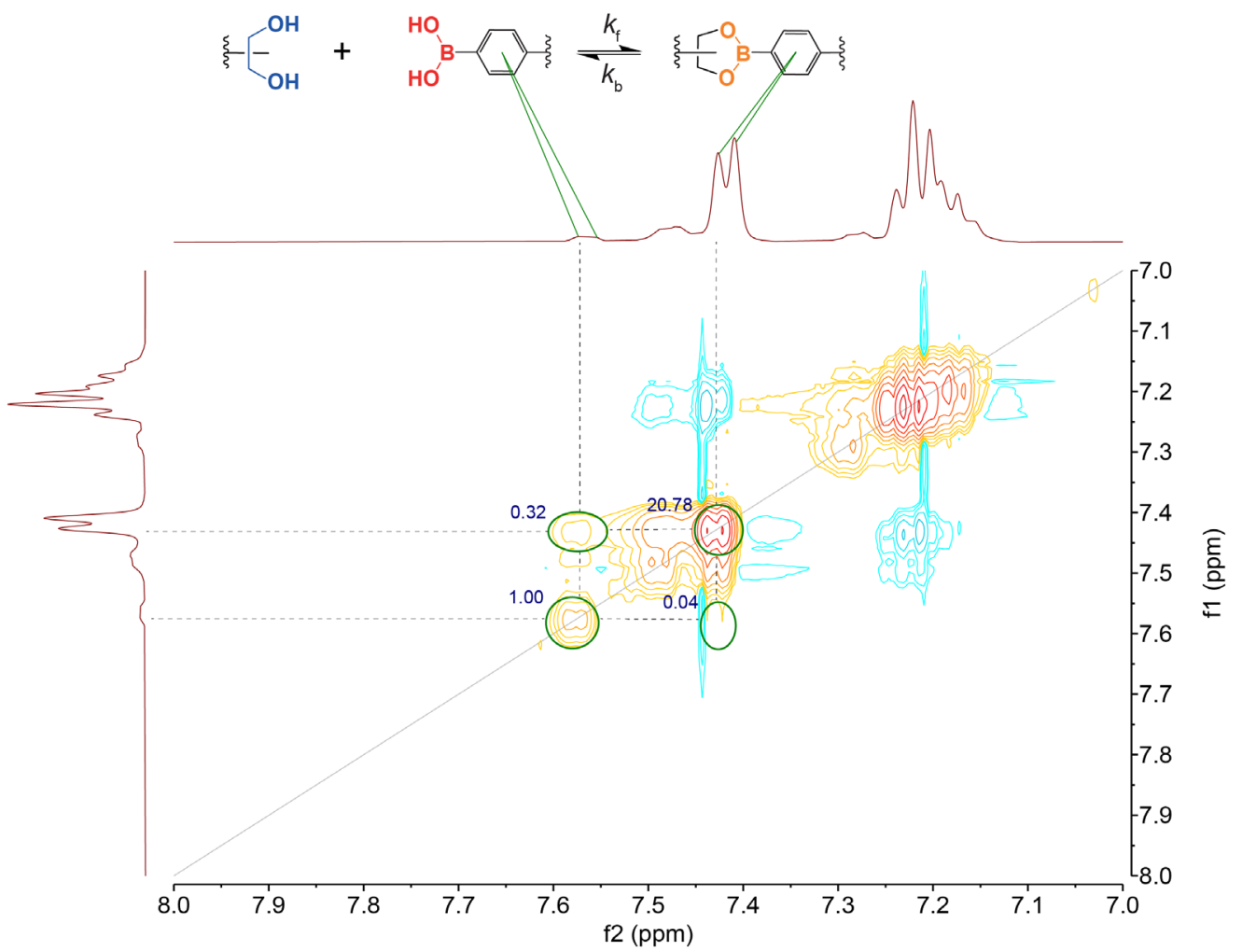

Figure S22. Representative 2D ${ }^{1} \mathrm{H}$ NMR spectrum of PBA $(25 \mathrm{mM})$ and fructose $(25 \mathrm{mM})$ mixed at $\mathrm{pH} 9$, forming a boronic ester $\left(400 \mathrm{MHz}, \mathrm{D}_{2} \mathrm{O}\right.$; NOESY pulse sequence, $\left.\tau_{\mathrm{m}}=1.0 \mathrm{~s}\right)$. 


\subsection{Shear rheometry}

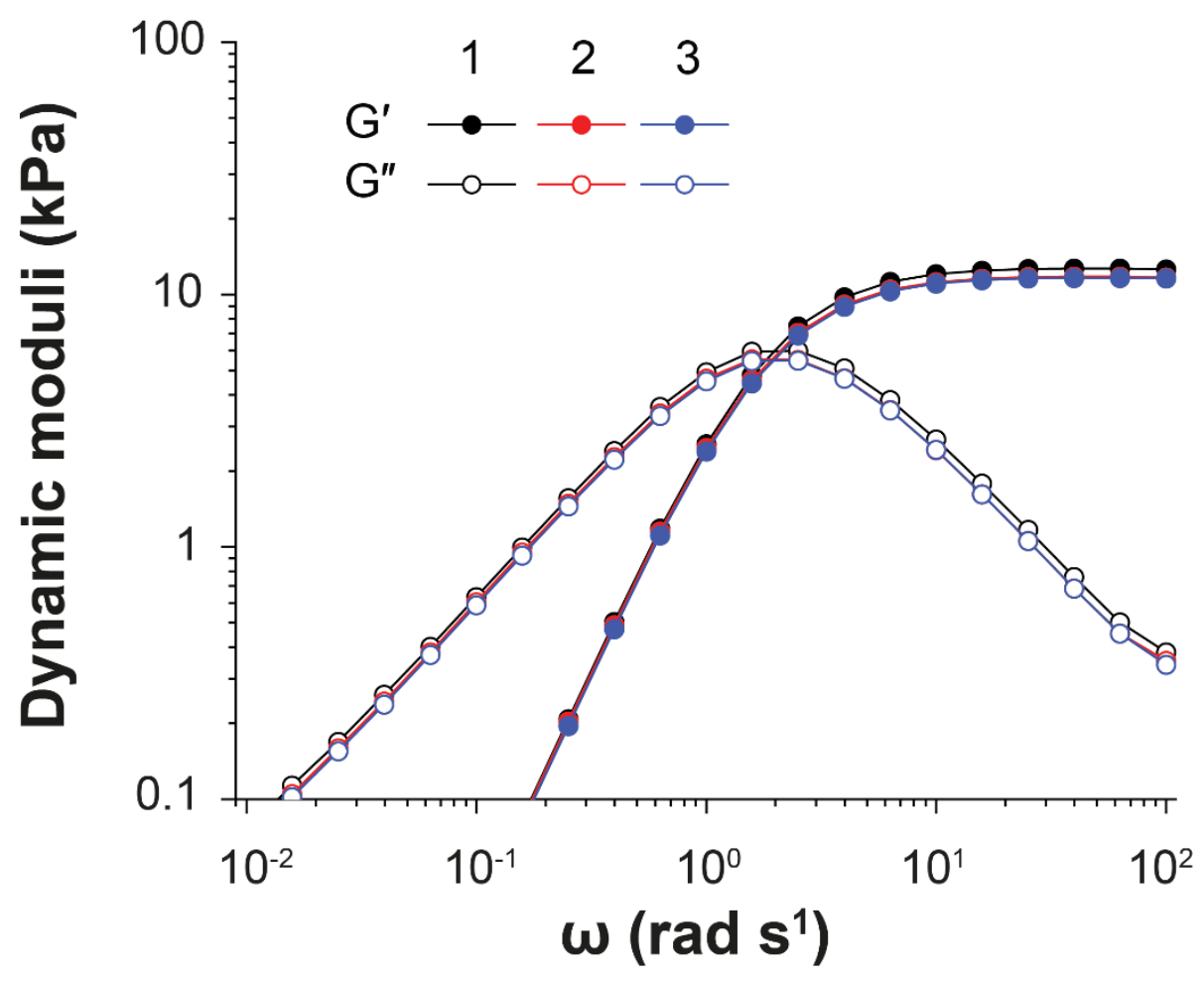

Figure S23. Shear rheometry constituted a reproducible method to characterize the time-dependent mechanical properties of the boronic ester gels (3 samples; PEG-PBA/GL, $10 \mathrm{wt} \%$, $\mathrm{pH} 8 ; \gamma=1 \%$ ).

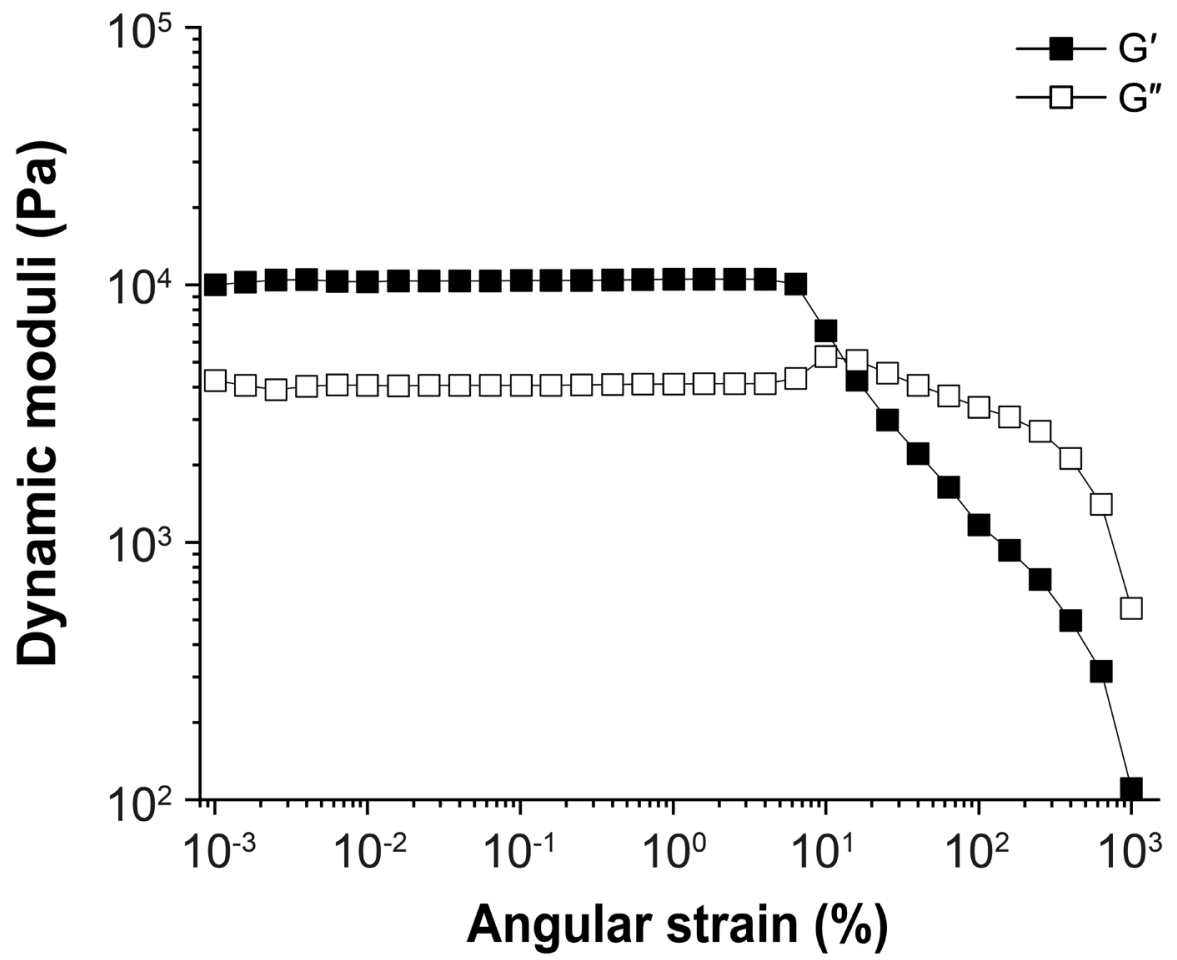

Figure S24. Strain sweep experiment showing the bounds of the linear viscoelastic region for a representative boronic ester-based hydrogel (PEG-PBA/GL, $10 \mathrm{wt} \%$, $\mathrm{pH} 7.5 ; \omega=10 \mathrm{rad} \mathrm{s}^{-1}$ ). 


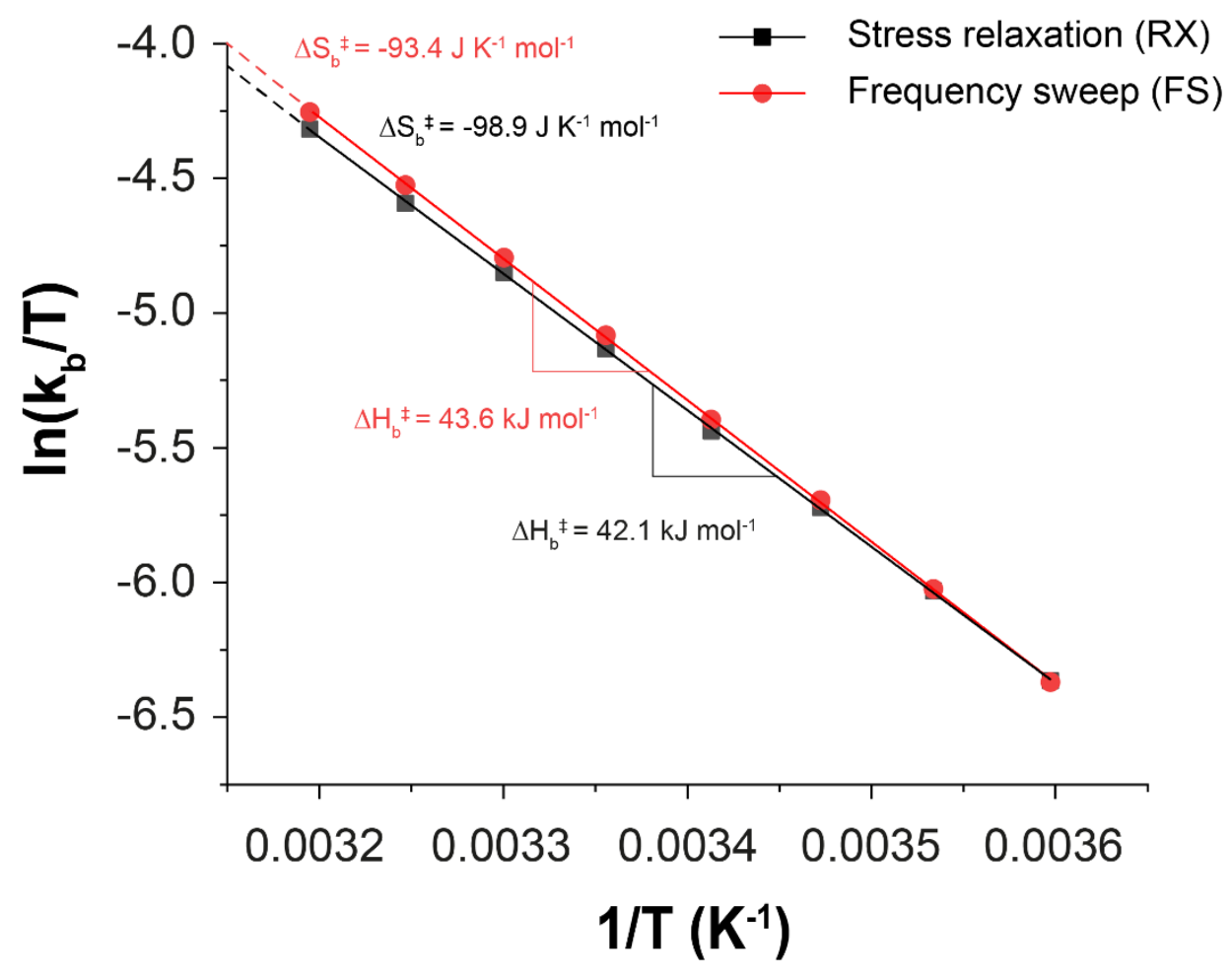

Figure S25. Eyring plots constructed with $\tau_{\mathrm{R}}$ obtained from stress relaxation (RX) and frequency sweep (FS) experiments yielded similar activation energies (PEG-PBA/GL, $10 \mathrm{wt} \%, \mathrm{pH} 8 ; \gamma=1 \%$ ). 


\section{References}

(1) M. J. Frisch, G. W. Trucks, H. B. Schlegel, G. E. Scuseria, M. A. Robb, J. R. Cheeseman, G. Scalmani, V. Barone, B. Mennucci, G. A. Petersson, H. Nakatsuji, M. Caricato, X. Li, H. P. Hratchian, A. F. Izmaylov, J. Bloino, G. Zheng, J. L. Sonnenberg, M. Had, and D. J. F.; Frisch, M. J.; Trucks, G. W.; Schlegel, H. B.; Scuseria, G. E.; Robb, M. A.; Cheeseman, J. R.; Scalmani, G.; Barone, V.; Mennucci, B.; Petersson, G. A.; Nakatsuji, H.; Caricato, M.; Li, X.; Hratchian, H. P.; Izmaylov, A. F.; Bloino, J.; Zheng, G.; Sonnenberg, J. L.; Hada, M.; Ehara, M.; Toyota, K.; Fukuda, R.; Hasegawa, J.; Ishida, M.; Nakajima, T.; Honda, Y.; Kitao, O.; Nakai, H.; Vreven, T.; Montgomery Jr., J. A.; Peralta, J. E.; Ogliaro, F.; Bearpark, M.; Heyd, J. J.; Brothers, E.; Kudin, K. N.; Staroverov, V. N.; Kobayashi, R.; Normand, J.; Raghavachari, K.; Rendell, A.; Burant, J. C.; Iyengar, S. S.; Tomasi, J.; Cossi, M.; Rega, N.; Millam, J. M.; Klene, M.; Knox, J. E.; Cross, J. B.; Bakken, V.; Adamo, C.; Jaramillo, J.; Gomperts, R.; Stratmann, R. E.; Yazyev, O.; Austin, A. J.; Cammi, R.; Pomelli, C.; Ochterski, J. W.; Martin, R. L.; Morokuma, K.; Zakrzewski, V. G.; Voth, G. A.; Salvador, P.; Dannenberg, J. J.; Dapprich, S.; Daniels, A. D.; Farkas, Ö.; Foresman, J. B.; Ortiz, J. V; Cioslowski, J.; Fox, D. J. Gaussian 09, Revision D.01. Gaussian Inc., Wallingford. 2009.

Adamo, C.; Barone, V. Toward Reliable Density Functional Methods without Adjustable Parameters: The PBE0 Model. J. Chem. Phys. 1999, 110, 6158-6170.

(3) Weigend, F.; Ahlrichs, R. Balanced Basis Sets of Split Valence, Triple Zeta Valence and Quadruple Zeta Valence Quality for H to Rn: Design and Assessment of Accuracy. Phys. Chem. Chem. Phys. 2005, 7, 3297. Hydrogels with PH-Regulated Mechanical Properties. Adv. Mater. 2015, 28, 86-91.

Tang, S.; Ma, H.; Tu, H. C.; Wang, H. R.; Lin, P. C.; Anseth, K. S. Adaptable Fast Relaxing Boronate-Based Hydrogels for Probing Cell-Matrix Interactions. Adv. Sci. 2018, 5, 1800638.

Bosch, L. I.; Fyles, T. M.; James, T. D. Binary and Ternary Phenylboronic Acid Complexes with Saccharides and Lewis Bases. Tetrahedron 2004, 60, 11175-11190. Lopalco, A.; Stella, V. J.; Thompson, W. H. Origins, and Formulation Implications, of the PK Difference between Boronic Acids and Their Esters: A Density Functional Theory Study. Eur. J. Pharm. Sci. 2018, 124, 10-16. Springsteen, G.; Wang, B. A Detailed Examination of Boronic Acid-Diol Complexation. Tetrahedron 2002, 58, 5291-5300. Brooks, W. L. A.; Deng, C. C.; Sumerlin, B. S. Structure-Reactivity Relationships in Boronic Acid-Diol Complexation. ACS Omega 2018, 3, 17863-17870.

(11) Yount, W. C.; Loveless, D. M.; Craig, S. L. Small-Molecule Dynamics and Mechanisms Underlying the Macroscopic Mechanical Properties of Coordinatively Cross-Linked Polymer Networks. J. Am. Chem. Soc. 2005, 127, 14488-14496. 
(13) Figueiredo, T.; Cosenza, V.; Ogawa, Y.; Jeacomine, I.; Vallet, A.; Ortega, S.; Michel, R.; Olsson, J. D. M.; Gerfaud, T.; Boiteau, J.-G.; Jing, J.; Harris, C.; Auzély-Velty, R. Boronic Acid and Diol-Containing Polymers: How to Choose the Correct Couple to Form “Strong” Hydrogels at Physiological PH. Soft Matter 2020, 16, 3628-3641.

(14) Lu, J.; Ma, D.; Hu, J.; Tang, W.; Zhu, D. Nuclear Magnetic Resonance Spectroscopic Studies of Pyridine Methyl Derivatives Binding to Cytochrome C. J. Chem. Soc. Dalt. Trans. 1998, No. 13, 2267-2274.

(15) Pross, A. Theoretical and Physical Principles of Organic Reactivity; John Wiley and Sons, 1995.

(16) Tang, S.; Olsen, B. D. Relaxation Processes in Supramolecular Metallogels Based on Histidine-Nickel Coordination Bonds. Macromolecules 2016, 49, 9163-9175.

(17) Parada, G. A.; Zhao, X. Ideal Reversible Polymer Networks. Soft Matter 2018, 14, 5186-5196.

(18) Mahmad Rasid, I.; Ramirez, J.; Olsen, B. D.; Holten-Andersen, N. Understanding the Molecular Origin of Shear Thinning in Associative Polymers through Quantification of Bond Dissociation under Shear. Phys. Rev. Mater. 2020, 4, 55602.

(19) Zhang, X.; Waymouth, R. M. 1,2-Dithiolane-Derived Dynamic, Covalent Materials: Cooperative Self-Assembly and Reversible Cross-Linking. J. Am. Chem. Soc. 2017, 139, 3822-3833.

(20) Rubinstein, M.; Colby, R. H. Polymer Physics, 1st ed.; Oxford University Press: Oxford, 2003.

(21) Mezger, T. G. The Rheology Handbook, 2nd ed.; Vincentz Network: Hannover, 2006.

(22) Akagi, Y.; Matsunaga, T.; Shibayama, M.; Chung, U.; Sakai, T. Evaluation of Topological Defects in Tetra-PEG Gels. Macromolecules 2010, 43, 488-493.

(23) Macosko, C. W.; Miller, D. R. A New Derivation of Average Molecular Weights of Nonlinear Polymers. Macromolecules 1976, 9 , 199-206. 